\title{
Control of 5-Hydroxytryptamine Release in the Dorsal Raphe Nucleus by the Noradrenergic System in Rat Brain. Role of $\alpha$-Adrenoceptors
}

\author{
A Bortolozzi' and F Artigas*,I \\ 'Department of Neurochemistry, Institut d' Investigacions Biomèdiques de Barcelona (CSIC), IDIBAPS, 08036 Barcelona, Spain
}

\begin{abstract}
The interactions between the brainstem serotonergic (5-hydroxytryptamine, 5-HT) and noradrenergic (NA) systems are important for the pathophysiology and treatment of affective disorders. We examined the influence of $\alpha$-adrenoceptors on 5-HT and NA release in the rat dorsal raphe nucleus (DR) using microdialysis. 5-HT and NA concentrations in DR dialysates were virtually suppressed by TTX and increased by veratridine. The local and systemic administration of the $\alpha_{1}$-adrenoceptor antagonist prazosin reduced the DR 5-HT output but not that of NA. The maximal $5-\mathrm{HT}$ reduction induced by local prazosin administration $(-78 \%$ at $100 \mu \mathrm{M})$ was more marked than by its systemic administration $(-43 \%$ at $0.3 \mathrm{mg} / \mathrm{kg}$ ). The local application of NA and desipramine, to increase the tone on DR $\alpha_{1}$-adrenoceptors, did not enhance 5 -HT release. The local $(100 \mu \mathrm{M})$ or systemic $(0.1-I \mathrm{mg} / \mathrm{kg}$ s.c.) administration of clonidine reduced $5-\mathrm{HT}$ and NA release ( -48 and $-79 \%$, respectively, at I $\mathrm{mg} / \mathrm{kg}$ ), an effect reversed by $\mathrm{RX}-82 \mathrm{I} 002$, which by itself increased both amines when given systemically. DSP-4 pretreatment prevented the effects of clonidine on 5-HT, suggesting the participation of $\alpha_{2}$-adrenoceptors on NA elements. Moreover, the systemic effect of clonidine on 5-HT (but not NA) was cancelled by lesion of the lateral habenula and by anesthesia, and was slightly enhanced by cortical transection. These data support the view that $\alpha_{1}$-adrenoceptors in the DR tonically stimulate 5-HT release, possibly at nearly maximal tone. Likewise, the 5-HT release is modulated by $\alpha_{2}$-adrenoceptors in NA neurons and in forebrain areas involved in the distal control of 5-HT neurons.

Neuropsychopharmacology (2003) 28, 42 I-434. doi: I 0.1038/sj.npp. 130006 I
\end{abstract}

Keywords: 5-hydroxytryptamine; $\alpha$-adrenoceptors; dorsal raphe nucleus; frontal cortex; habenula; noradrenaline

\section{INTRODUCTION}

The dorsal raphe nucleus (DR) of the midbrain contains most serotonergic (5-hydroxytryptamine, 5-HT) neurons that project to the forebrain (Dahlström and Fuxe, 1964). 5HT neurons are involved in many physiological functions and are the cellular target of a large array of drugs used to treat psychiatric illnesses (Jacobs and Azmitia, 1992; Montgomery, 1994; Meltzer, 1999). In particular, the vast majority of antidepressant drugs increase the serotonergic activity by directly or indirectly interfering with the mechanisms controlling the synaptic (extracellular) concentration of 5-HT, such as reuptake or deamination. Thus, the selective serotonin reuptake inhibitors (SSRIs) represent over $80 \%$ of the world antidepressant market (Heal and Cheetham, 1997). However, antidepressant drugs that

\footnotetext{
*Correspondence: Dr F Artigas; Department of Neurochemistry, Institut d' Investigacions Biomèdiques de Barcelona (CSIC), IDIBAPS, Rosselló, I6I, 6th floor, 08036 Barcelona, Spain, Tel: +3493 36383 I5, Fax: +3493 363 830।, E-mail: fapnqi@iibb.csic.es

Received 27 February 2002; revised 10 May 2002; accepted 16 July 2002

Online publication: 19 July 2002 http://www.acnp.org/citations/ Npp071902350
}

inhibit noradrenaline (NA) reuptake as well may be more effective than SSRIs in the treatment of depression (DUAG, 1986, 1990; Thase et al, 2001).

The activity of DR serotonergic neurones is tightly controlled by $5-\mathrm{HT}_{1 \mathrm{~A}}$ autoreceptors (Blier and de Montigny, 1987; Sprouse and Aghajanian, 1987) and by afferent pathways from several brain areas (Jacobs and Azmitia, 1992). Among these, the catecholamine groups (Baraban and Aghajanian, 1980; Peyron et al, 1996), the lateral habenula (Aghajanian and Wang, 1977; Stern et al, 1981), and the medial prefrontal cortex (Aghajanian and Wang, 1977; Sesack et al, 1989; Hajós et al, 1998; Peyron et al, 1998; Celada et al, 2001; Martín-Ruiz et al, 2001a) play a major role.

The anatomical relationships between the DR and the pontine noradrenergic nuclei suggest the existence of a functional interaction between noradrenergic and serotonergic neurons. Both neuronal groups are REM-off (AstonJones et al, 1991; Jacobs and Azmitia, 1992) and previous studies have shown that the discharge rate and release of serotonergic neurons is under the excitatory control of $\alpha_{1}$ adrenoceptors (Baraban and Aghajanian, 1980; Pan et al, 1994). Thus, the $\alpha_{1}$-adrenoceptor agonist phenylephrine, applied in the DR, reversed the cessation of serotonergic 
discharge occurring during REM sleep in cats (Sakai and Crochet, 2000). Likewise, in deafferented midbrain slices containing the DR, bath application of phenylephrine restores normal firing in serotonergic neurons. On the other hand, the activation of $\alpha_{2}$-adrenoceptors has been shown to reduce the firing activity of serotonergic neurons and the release of 5-HT in forebrain structures (Svensson et al, 1975; Tao and Hjorth, 1992; Mongeau et al, 1997).

The interplay between both aminergic systems is likely involved in common physiological aspects of serotonergic and noradrenergic neurons, such as their parallel change of activity across the sleep-wake cycle, which suggests coordinate actions in the forebrain through the activation of postsynaptic receptors. It is also likely that these interactions play a role in the reported superior clinical efficacy of antidepressants acting on both neurotransmitter systems (DUAG, 1986, 1990; Thase et al, 2001). In an attempt to better understand the control of the serotonergic system by noradrenergic inputs, we recently examined the effects of $\alpha_{1}$ - and $\alpha_{2}$-adrenoceptor ligands on the release of 5-HT in the median raphe nucleus (Adell and Artigas, 1999). Here we extend our study to examine the effects of modulating $\alpha_{1}$ - and $\alpha_{2}$-adrenoceptor-mediated transmission on the release of 5-HT and NA in the DR of the freely moving rat using in vivo microdialysis.

\section{MATERIALS AND METHODS}

\section{Animals}

Male Wistar rats (Iffa Credo, Lyon, France) weighing 280$320 \mathrm{~g}$ at the beginning of the experiments were used. The animals were housed in groups of four per cage until the onset of the experiments, and kept under a controlled temperature of $22 \pm 2^{\circ} \mathrm{C}$ and a $12 \mathrm{~h}$ lighting cycle (lights on at 07:00). After surgery, rats were housed individually. Food and water were always freely available throughout the experiments. All experimental procedures were in strict compliance with the Spanish legislation and the European Communities Council Directive on 'Protection of Animals Used in Experimental and Other Scientific Purposes' of 24 November 1986 (86/609/EEC).

\section{In Vivo Microdialysis}

Concentric microdialysis probes were constructed with $20 \mathrm{~mm}$ long 25-gauge stainless-steel tubing (A-M Systems, Everett, WA, USA). The inflow and outflow lines inserted into the 25-gauge tubing consisted of a fused silica capillary tubing of $110 \mu \mathrm{m}$ OD and $40 \mu \mathrm{m}$ ID (Polymicro Technologies, Phoenix, AZ, USA). Dialysis membranes were made from hollow cuprophan fibers with $252 \mu \mathrm{m}$ OD, $220 \mu \mathrm{m}$ ID and $5000 \mathrm{Da}$ molecular weight cutoff (GFE09, Gambro, Lund, Sweden). The total length of the dialysis membrane exposed to the tissue was $1.5 \mathrm{~mm}$ in the DR and $4 \mathrm{~mm}$ in the dorsal striatum. To reduce the void volume, narrow-bore $(0.15 \mathrm{~mm}$ ID) FEP tubing (Metalant $\mathrm{AB}$, Stockholm, Sweden) was used in the microdialysis system. After an injection of $60 \mathrm{mg} / \mathrm{kg}$ of sodium pentobarbital, the rats were placed in a stereotaxic frame (David Kopf Instruments, Tujunga, CA, USA) and a dialysis probe was implanted in the DR and secured to the skull with anchor screws and dental cement. Stereotaxic coordinates (in $\mathrm{mm}$ ) from bregma and skull surface were AP $-7.8, \mathrm{~L}-3.1, \mathrm{DV}-7.5$, with a lateral angle of $30^{\circ}$ to avoid obstruction of the cerebral aqueduct, for the DR, and AP +0.2, L - 3.0, DV -8.0 for dorsal striatum (Paxinos and Watson, 1986). After a recovery period of $20-24 \mathrm{~h}$, rats were placed in a plastic cage with a mounted liquid swivel system (Instech Laboratories, Plymouth Meeting, PA, USA). The probes were perfused at a constant rate of $1.5 \mu \mathrm{l} / \mathrm{min}$ with an artificial cerebrospinal fluid (aCSF; $\mathrm{NaCl} 125 \mathrm{mM}, \mathrm{KCl}$ $2.5 \mathrm{mM}, \mathrm{MgCl}_{2} 1.18 \mathrm{mM}$, and $\mathrm{CaCl}_{2} 1.26 \mathrm{mM}$ ), containing $1 \mu \mathrm{M}$ of citalopram (H Lundbeck A/S, Copenhagen-Valby, Denmark). The dialysate level of 5-HT represents a balance between release and reuptake of the transmitter. With the partial blockade of the reuptake process by the addition of citalopram to the perfusion fluid, the concentration of 5-HT in dialysate samples reflects mainly the release of the transmitter. Dialysate samples of $30 \mu \mathrm{l}$ were collected at 20 min intervals into polypropylene microcentrifuge vials containing $5 \mu \mathrm{l}$ of $10 \mathrm{mM}$ perchloric acid. After an initial $1 \mathrm{~h}$ sample of dialysate was discarded, four samples were collected to establish stable baseline levels of 5-HT and NA.

\section{HPLC Analysis}

Dialysate samples were assayed for 5-HT and NA by HPLC using an Ultrasphere $3 \mu \mathrm{m}$ column $(7.5 \mathrm{~cm} \times 0.46 \mathrm{~cm}$; Beckman, San Ramon, CA, USA) and determined with an amperometric detector Hewlett-Packard 1049 (Palo Alto, CA, USA), set at a potential of $+0.75 \mathrm{~V}$. Samples were processed immediately after collection to prevent degradation of NA. The mobile phase consisted of $0.1 \mathrm{M} \mathrm{KH}_{2} \mathrm{PO}_{4}$, $2.3 \mathrm{mM}$ octyl sodium sulfate, $0.1 \mathrm{mM}$ EDTA ( $\mathrm{pH} 2.6$ adjusted with phosphoric acid) and $15 \%$ methanol, and was pumped at $0.5 \mathrm{ml} / \mathrm{min}$. With these conditions, the respective retention times of NA and 5-HT were 3.5 and $16 \mathrm{~min}$, approximately (Figure 1a).

In experiments involving lesions of the noradrenergic system with DSP-4, rats were killed at the conclusion of the dialysate experiments, and brain tissue processed according to a method described elsewhere (Adell et al, 1989) to examine the magnitude of NA depletion. Briefly, each brain was quickly removed and placed over a cold plate. Coronal cuts were made with a blade and the frontal cortex was dissected out. Tissue samples were weighed and homogenized in $800 \mu \mathrm{l}$ of ice-cold $0.4 \mathrm{mM}$ perchloric acid containing $5.0 \mathrm{mM}$ sodium metabisulfite, $8.3 \mathrm{mM}$ cysteine, and $0.3 \mathrm{mM}$ EDTA. After centrifugation at $12000 \mathrm{~g}(30 \mathrm{~min}$, $4{ }^{\circ} \mathrm{C}$ ), aliquots of the supernatants were analyzed for NA and 5-HT.

\section{Chemicals}

The HPLC reagents were of analytical grade and obtained from Merck (Darmstadt, Germany). 5-HT oxalate, 8-OHDPAT $(( \pm)$-8-hydroxy-2-(di- $n$-propylamino)tetralin hydrobromide), clonidine hydrochloride, desipramine hydrochloride, DSP-4 ( $\mathrm{N}$-(2-chloroethyl)- $\mathrm{N}$-ethyl-2-bromobenzylamine hydrochloride), NA bitartrate, prazosin hydrochloride, tetrodotoxin (TTX), veratridine, WAY-100635 ( $N$-\{2-[4-(2-methoxyphenyl)-1-piperazinyl] ethyl\}- $N$-(2-pyridinyl) cyclohexanecarboxamide trihydrochloride), and 
a
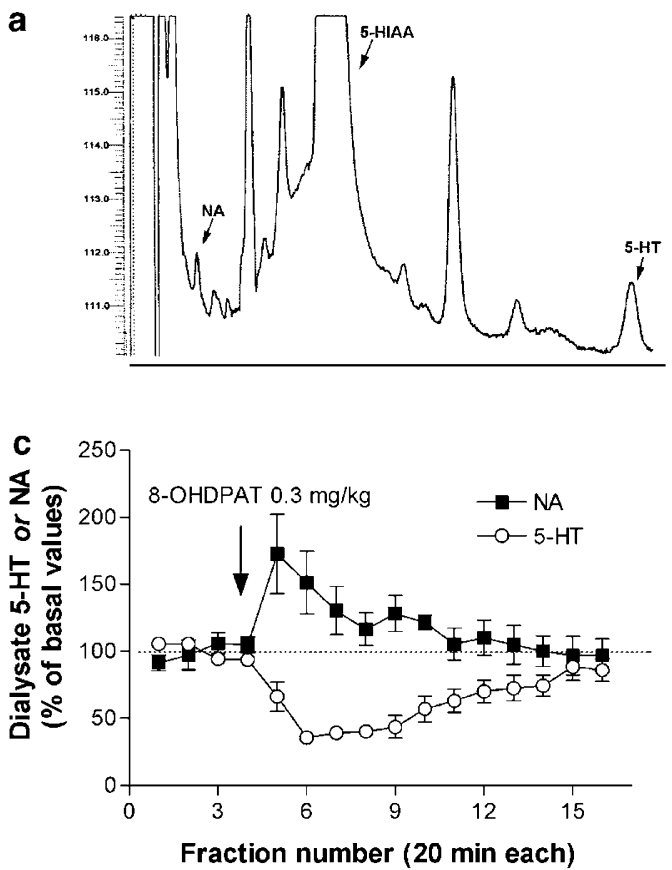
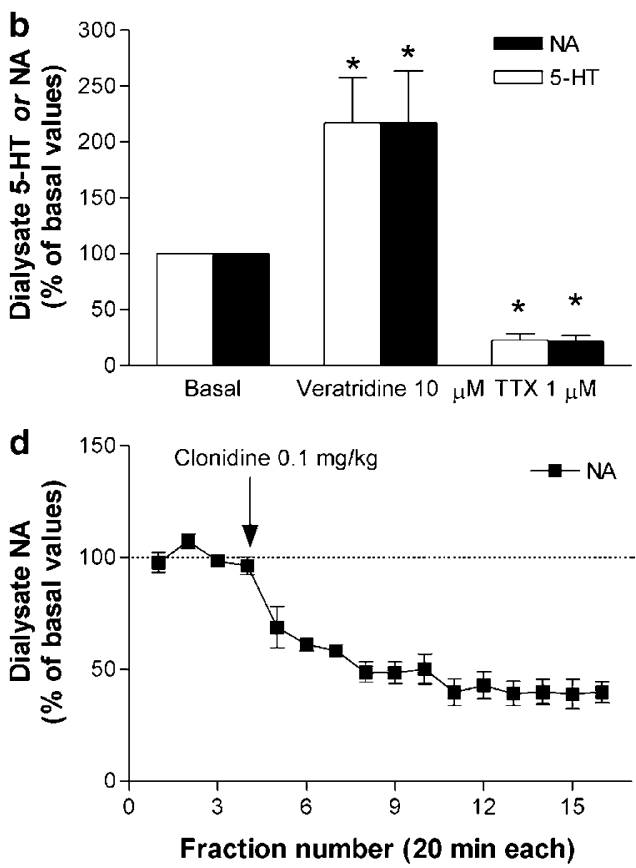

Figure I (a) HPLC trace of a baseline dialysate sample from the DR showing the presence of NA and 5-HT (approximate retention times 3.5 and I6 min, respectively). The absolute values for both neurotransmitters in this particular sample were 8.5 and $27 \mathrm{fmol}$, respectively. (b) Bar graph showing the effects of the local perfusion of veratridine $(10 \mu \mathrm{M})$ and tetrodotoxin $(I \mu \mathrm{M})$ on the concentration of 5-HT and NA in DR dialysates $(n=5)$. (c) and $(\mathrm{d})$ Effect of the administration of the respective autoreceptor agonists $8-\mathrm{OH}$-DPAT $(0.3 \mathrm{mg} / \mathrm{kg}$ s.c.; $n=5)$ and clonidine $(0.1 \mathrm{mg} / \mathrm{kg}$ s.c.; $n=8)$ on dialysate 5 -HT and NA, respectively. The enhancement of NA output by $8-\mathrm{OH}$-DPAT is also shown. $* 0<0.0 \mathrm{I}$ vs baseline.

yohimbine hydrochloride were purchased from Sigma/RBI (St Louis, MO, USA). RX-821002 (2-(2,3-dihydro-2-methoxy-1,4-benzodioxin-2-yl)-4,5-dihydro- $1 H$-imidazole hydrochloride) was from Tocris (Bristol, UK). Citalopram was gently provided by Lundbeck A/S (Copenhagen-Valby, Denmark). Drugs were systemically administered at the doses and routes indicated or locally applied by reverse dialysis at the stated concentrations after appropriate dilutions in the dialysis fluid. The DSP-4 solutions were prepared immediately before use. Concentrated $(1 \mathrm{mM})$ drug solutions were stored at $-80^{\circ} \mathrm{C}$ and working solutions were prepared every day. When necessary, the $\mathrm{pH}$ of the concentrated solutions was adjusted to $\sim 6-7$. Control groups for the effects or systemic drug administration were injected with vehicle whereas controls for local drug administration were perfused with aCSF for the entire experiment.

At the conclusion of the experiments, rats were given an overdose of sodium pentobarbital, and the placement of the dialysis probes was examined by perfusing fast green dye and visual inspection of the probe track after cutting the brain at the level of the DR or striatum.

\section{Brain Lesions}

To examine the involvement of $\alpha$-adrenoceptors outside the DR in the actions of clonidine and prazosin, we performed several lesions. These included the treatment with the noradrenergic neurotoxin DSP-4, the electrolytic lesion of the lateral habenula, known to control the DR through the habenulo-raphe pathway, and cortical transection, to remove direct afferents from the medial prefrontal cortex that control the activity of 5-HT and NA neurons (Aghajanian and Wang, 1977; Stern et al, 1981; Hajós et al, 1998; Jodo et al, 1998; Celada et al, 2001). The lesion of the NA system was carried out by administration of DSP-4 $(40 \mathrm{mg} / \mathrm{kg}$ i.p.) $60 \mathrm{~min}$ after the injection of the selective serotonin uptake inhibitor fluoxetine $(10 \mathrm{mg} / \mathrm{kg}$ i.p.), to prevent concurrent damage of serotonergic neurons (Tellez et al, 1999). Rats were used 5-6 days after DSP-4 treatment.

Bilateral electrolytic lesions of the lateral habenula were performed with a Grass stimulating unit S-48 using bipolar electrodes (the distance between electrodes was $0.7 \mathrm{~mm}$ ). A current intensity of $2 \mathrm{~mA}$ for $10 \mathrm{~s}$ was used to produce the lesions. Stereotaxic coordinates for the placement of electrodes were AP $-3.5, \mathrm{~L} \pm 0.6, \mathrm{DV}-4.8$ (tip).

Transection of the frontal cortex was performed using a fine needle $(0.6 \mathrm{~mm}$ diameter $)$, which was stereotaxically positioned at AP +1.0, DV -6.0, L from 0.0 to 4.0, in sodium pentobarbital $(60 \mathrm{mg} / \mathrm{kg}$ i.p.) anesthetized rats. The needle was moved from the midline bilaterally (from 0.0 to \pm 4.0 ) without damaging the sinus. Drug administration was performed $22-24 \mathrm{~h}$ after the frontocortical transection. At the end of microdialysis experiments, rats were killed with an overdose of sodium pentobarbital and perfused transcardially with $0.9 \%$ physiological saline followed by $10 \%$ formalin. The brains were removed and stored in $10 \%$ formalin before being sectioned $(40 \mu \mathrm{m})$ with a cryostat in the coronal or sagital plane. Brain sections were then stained with neutral red, according to standard procedures to examine the extent of the habenular lesions and frontocortical transections. 


\section{Data Treatment and Statistical Analysis}

Baseline 5-HT and NA values are given in $\mathrm{fmol} / 30 \mu \mathrm{l}$ and were calculated averaging the four predrug samples. Unless otherwise specified, all samples were expressed as a percentage of the mean baseline. In some instances, the 5HT or NA values have been averaged to examine drug effect over a certain time period, indicated in the text. Overall drug effects have been assessed by one- or two-way repeated measures ANOVA with treatment and time as main factors. One-way ANOVA or Student's $t$-test for independent data have also been used. All statistical procedures were performed using the Statistica software for Windows (StatSoft, Inc., Tulsa, OK, USA). Data are given as means \pm SEM. Statistical significance was set at the 95\% level (two-tailed).

Table I Effects of DSP-4 Pretreatment, Electrolytic Lesion of Lateral Habenula and Cortical Transection on Baseline 5-HT and NA Dialysate Values in the DR

\begin{tabular}{llc}
\hline Group & $\begin{array}{l}\text { Baseline 5-HT } \\
\text { (fmol/fraction) }\end{array}$ & $\begin{array}{l}\text { Baseline NA } \\
\text { (fmol/fraction) }\end{array}$ \\
\hline No pretreatment & $35.58 \pm 1.42(105)$ & $9.63 \pm 0.58(74)$ \\
DSP-4 & $24.32 \pm 1.45 * *(3 \mid)$ & $15.47 \pm 2.18 *(29)$ \\
Lateral habenula-lesioned & $25.9 \mid \pm 2.13(14)$ & $9.80 \pm 0.40(14)$ \\
Cortical transection & $25.30 \pm 1.27(14)$ & $13.53 \pm 0.55(14)$ \\
\hline
\end{tabular}

Data are means \pm SEM of the number of animals shown in brackets.

* $p<0.05 ; * * 0=0.06$ with respect to nonlesioned animals (Tukey test postANOVA).

\section{RESULTS}

Sensitivity of Dialysate 5-HT and NA in the DR to Nerve Impulse

Figure 1a shows a typical HPLC trace of a dialysate sample from the DR. Both the NA and 5-HT peaks were free from interfering compounds. In order to validate the HPLC method, we examined the sensitivity of the 5-HT and NA peaks to the local application of veratridine and TTX. The local application of veratridine $(10 \mu \mathrm{M})$ for $20 \mathrm{~min}$ doubled the concentration of 5 - HT $(n=5, p<0.01$, Duncan test post-ANOVA, Figure 1b). Following stabilization of the 5-HT values, we applied TTX $(1 \mu \mathrm{M})$ for $2 \mathrm{~h}$. TTX rapidly reduced dialysate 5-HT concentration to $\sim 20 \%$ of baseline values from 40 min after application onwards $(p<0.01$, Duncan test post-ANOVA, Figure $1 \mathrm{~b})$. Veratridine increased dialysate NA to an extent similar to that of 5-HT $(n=5, p<0.002$, Duncan test post-ANOVA) and TTX reduced it maximally to $\sim 20 \%$ of baseline $(p<0.001$, Duncan test post-ANOVA, Figure $1 \mathrm{~b})$. Furthermore, the treatment of rats with 8-OH-DPAT $(0.3 \mathrm{mg} / \mathrm{kg}$ s.c., $n=5)$ and clonidine $(0.1 \mathrm{mg} / \mathrm{kg}$ s.c., $n=8)$, agonists of $5-\mathrm{HT}_{1 \mathrm{~A}}$ and $\alpha_{2}$-adrenoceptors, respectively, markedly reduced the concentration of 5-HT and NA in DR dialysates to ca. 25 and $50 \%$ of baseline, respectively $\left(\mathrm{F}_{15,60}=7.95, p<0.00001\right.$ and $\mathrm{F}_{15,45}=9.82$, $p<0.00001$ for 8 -OH-DPAT and clonidine, respectively, Figures 1c and d). Baseline 5-HT and NA values in dialysates from the DR of rats without pretreatment are shown in Table 1.

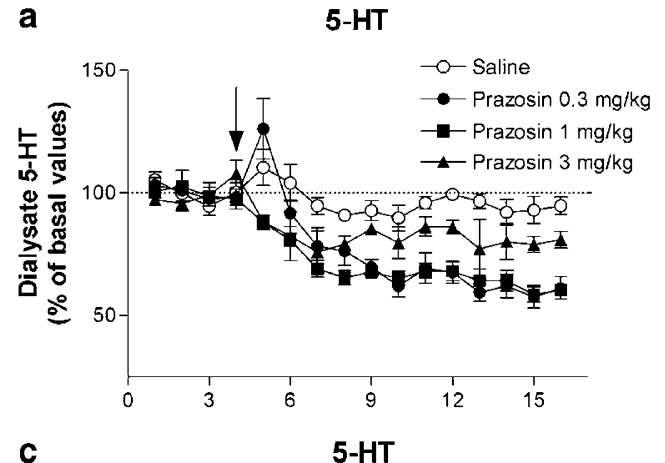

b NA
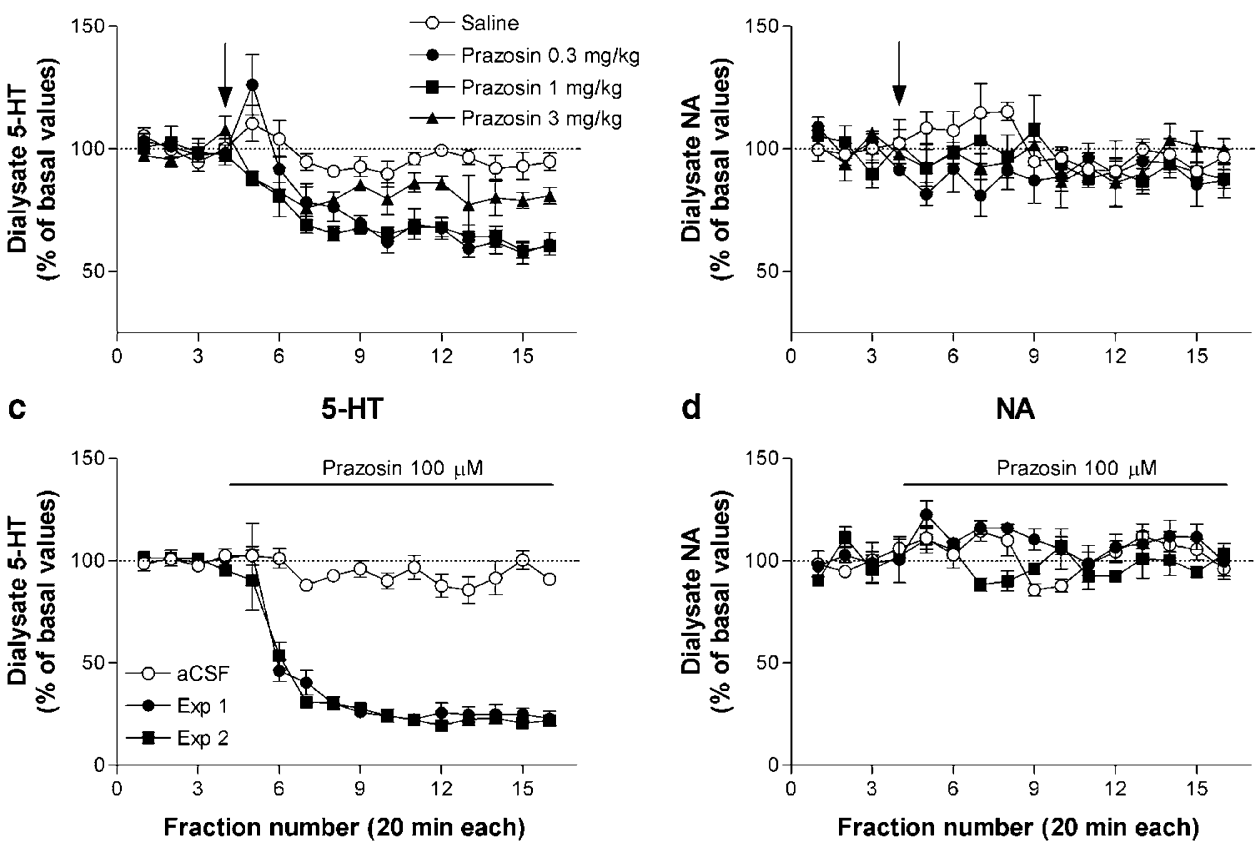

Figure 2 Effect of the systemic ( $a, b)$ and local $(c, d)$ administration of the $\alpha_{1}$-adrenoceptor antagonist prazosin on the 5-HT and NA output in the DR Prazosin reduced the 5-HT release at the three doses examined and did not affect NA. Note the absence of a linear dose-response in the effect of systemic prazosin on $5-H T$ (a). The administration of prazosin by reverse dialysis in the DR ( $100 \mu \mathrm{M}$, uncorrected for probe recovery) markedly reduced the 5-HT output (c) and did not affect NA output (d). (c) Results of two different experiments performed 10 months apart. Data from 4 to 8 rats/group except prazosin $3 \mathrm{mg} / \mathrm{kg}(n=3)$. See results for statistical analysis. 


\section{Modulation of 5-HT Release by $\alpha_{1}$-Adrenoceptors}

The systemic administration of prazosin $(0.3 \mathrm{mg} / \mathrm{kg}$ s.c.) reduced maximally the 5 -HT output in the DR to $60 \%$ of baseline without altering that of NA (Figures $2 a$ and $b$ ). The administration of saline did not significantly alter the release of either transmitter. Two-way ANOVA showed a significant effect of the time $\left(\mathrm{F}_{15,165}=12.1, p<0.000001\right)$ and the time $\times$ treatment interaction $\left(\mathrm{F}_{15,165}=5.8\right.$, $p<0.000001)$ for 5 -HT. Prazosin $(0.3 \mathrm{mg} / \mathrm{kg}$ s.c.) reduced the 5-HT output similarly when probes were perfused with an aCSF devoid of citalopram. Thus, the average reductions (fractions 6-16) were $69 \pm 4$ and $70 \pm 4 \%$ of baseline in the presence and absence of citalopram, respectively (n.s., Student's $t$-test). Higher doses of prazosin ( 1 and $3 \mathrm{mg} / \mathrm{kg}$ ) did not reduce 5-HT further (Figure 2a). Thus, prazosin $1 \mathrm{mg} / \mathrm{kg}$ reduced $5-\mathrm{HT}$ to the same extent as $0.3 \mathrm{mg} / \mathrm{kg}$, whereas the $5-\mathrm{HT}$ reduction produced by the $3 \mathrm{mg} / \mathrm{kg}$ dose was less marked than that of 0.3 and $1 \mathrm{mg} / \mathrm{kg}$ (Figure 2a).

The local application of $100 \mu \mathrm{M}$ prazosin in the DR, a concentration known to maximally reduce 5-HT output in the MnR (Adell and Artigas, 1999), reduced that in the DR to $22 \pm 3 \%$ of baseline (Figure 2c). Two-way ANOVA revealed a significant effect of the treatment $\left(\mathrm{F}_{1,11}=5.7\right.$, $p<0.04)$ time $\left(\mathrm{F}_{11,165}=15.4, p<0.000001\right)$ and the time$\times$ treatment interaction $\left(\mathrm{F}_{11,165}=10.7, p<0.000001\right)$. Given the marked difference between the local and systemic effect of prazosin on the 5-HT output, we performed a second local experiment several months later, which yielded exactly the same results (Exp. 2, Figure 2c). Prazosin infusion did not significantly alter the NA output in the DR (Figure 2).

These results support the fact that $\alpha_{1}$-adrenoceptors tonically stimulate the 5-HT release in the DR. To examine whether 5-HT output could be further enhanced by an increased noradrenergic tone, we locally infused the NA reuptake blocker desipramine in the DR. In the dorsal striatum, desipramine $(10-100 \mu \mathrm{M})$ increased the NA output to $\sim 5$-fold of baseline $\left(\mathrm{F}_{21,126}=23.2, p<0.00001\right.$, one-way ANOVA) without significantly altering the 5-HT output (Figure 3a). We therefore used $100 \mu \mathrm{M}$ desipramine in subsequent experiments in the DR. Desipramine perfusion in the DR significantly increased the NA output to a maximal concentration of $216 \pm 25 \%$ of baseline (fractions $1-10, \mathrm{~F}_{9,27}=7.5, p<0.00002$ ) without significantly affecting the 5 -HT output (fractions $1-10, \mathrm{~F}_{9,27}=0.9, p=0.55$ ). The subsequent co-application of prazosin did not alter the effect of desipramine on NA output and significantly reduced the 5-HT output to $48 \pm 9 \%$ of baseline (fractions $7-16, \quad \mathrm{~F}_{9,27}=9.1, \quad p<0.0000003$ ) (Figure 3b). A further attempt to increase the tone on $\alpha_{1}$-adrenoceptors was carried out by locally perfusing $10 \mathrm{nM} \mathrm{NA}$ in addition to desipramine. This procedure maximally enhanced dialysate NA 15-fold (data not shown) but did not alter the 5-HT output in the DR (Figure 3c). As in previous experiments, the application of $100 \mu \mathrm{M}$ prazosin significantly reduced the 5 -HT output (fractions $7-16, \mathrm{~F}_{9,27}=3.5, p<0.005$ ).

\section{Modulation of 5-HT Release by $\alpha_{2}$-Adrenoceptors}

The systemic administration of clonidine $(0.1$ and $1 \mathrm{mg} / \mathrm{kg}$ s.c.) reduced the 5-HT output in the DR in a dosedependent manner $\left(F_{15,225}=16.85, p<0.0000001\right.$, time a

\section{Dorsal striatum}

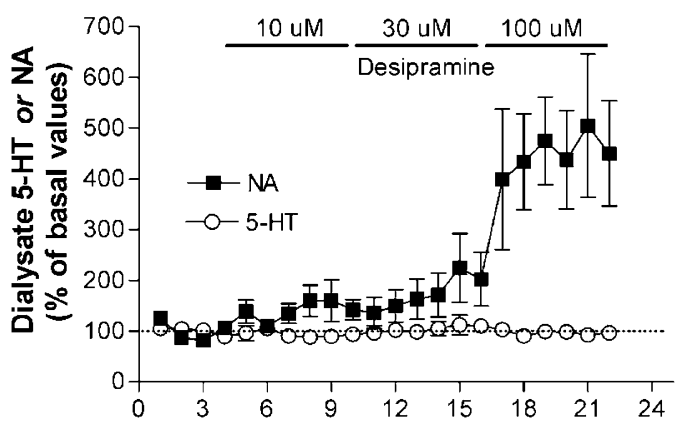

b

DR

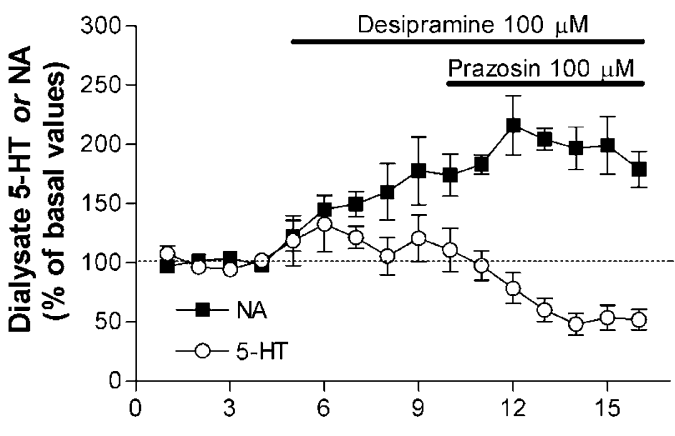

C

DR

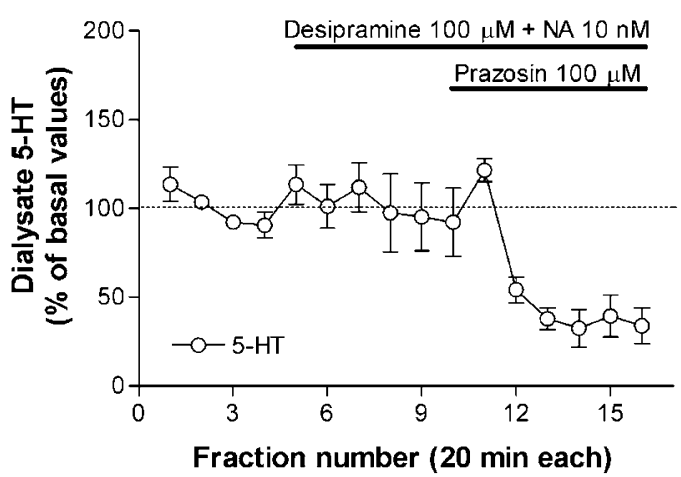

Figure 3 (a) The application of desipramine (10-100 $\mu \mathrm{M}, 6$ fractions each) in the dorsal striatum increased the NA output in a concentrationdependent manner and did not alter the 5-HT output. (b) In the DR, the perfusion of desipramine also increased the NA output without significantly affecting 5-HT. The subsequent co-perfusion of prazosin $(100 \mu \mathrm{M})$ significantly reduced the 5-HT output. (c) The perfusion of desipramine $100 \mu \mathrm{M}$ in combination with $10 \mathrm{nM}$ NA did not alter the 5-HT output in the DR. As in previous experiments, the perfusion of prazosin markedly reduced the 5-HT output. Data from 4 to 7 rats/group. See results for statistical analysis.

effect; $\mathrm{F}_{30,225}=4.59, p<0.000001$, time $\times$ group interaction) (Figure $4 \mathrm{a})$. In a pilot experiment, a lower dose $(0.03 \mathrm{mg} / \mathrm{kg}$ s.c.) did not alter the 5-HT output (data not shown). The maximal reduction was noted at $1 \mathrm{mg} / \mathrm{kg}$, reaching $52 \pm 5 \%$ of baseline.

Clonidine administration also reduced the NA output in the DR in a dose-dependent manner $\left(\mathrm{F}_{2,14}=5.64, p<0.01\right.$, group effect; $\mathrm{F}_{15,210}=17.42, \quad p<0.000001$, time effect; $\mathrm{F}_{30,210}=3.66, p<0.000001$, time $\times$ group interaction). The effect on NA was notably more marked than that on 
5-HT

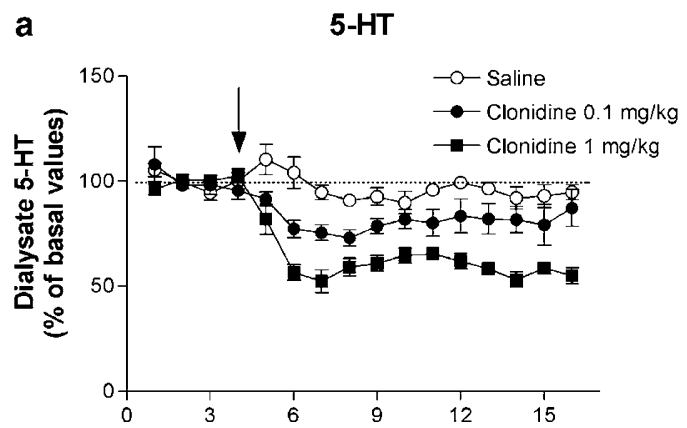

C

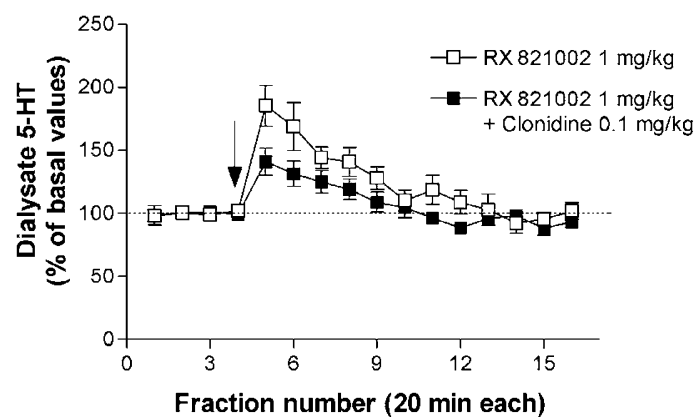

b

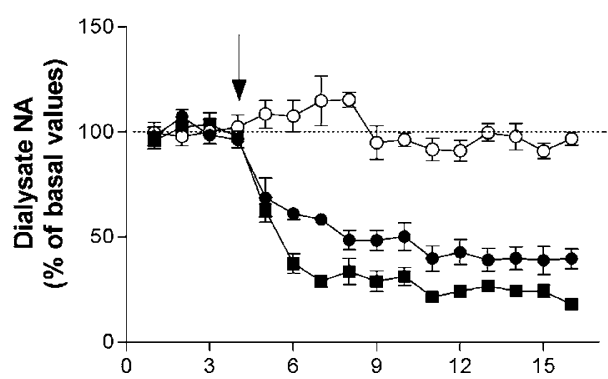

d

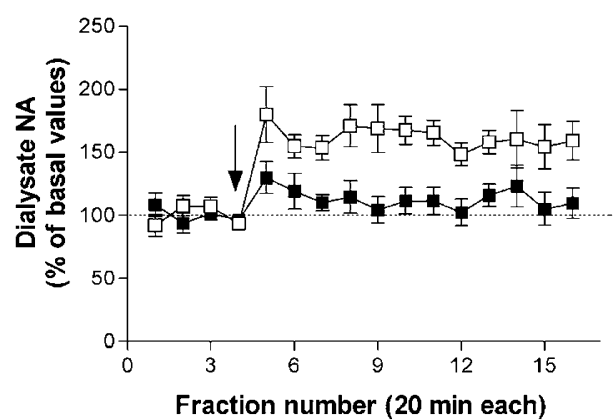

Figure 4 Effects of the s.c. administration of the $\alpha_{2}$-adrenoceptor agonist clonidine on the output of 5-HT and NA in the DR: (a) reduction of the 5-HT output produced by the s.c. administration of 0.1 and I mg/ $/ \mathrm{kg}$ clonidine; (b) effect of the same clonidine doses on the NA output; (c) and (d) effect of the $\alpha_{2}$ adrenoceptor antagonist RX-82 I002 (I mg/kg s.c.) alone or in combination with clonidine $0.1 \mathrm{mg} / \mathrm{kg}$ s.c. on the 5-HT and NA output in the DR. RX-82 I002 significantly increased 5-HT and NA concentrations and fully antagonized the effect of clonidine on both amines. Controls (open circles) received saline. Data from 5 to 8 rats/group. See results for statistical analysis.

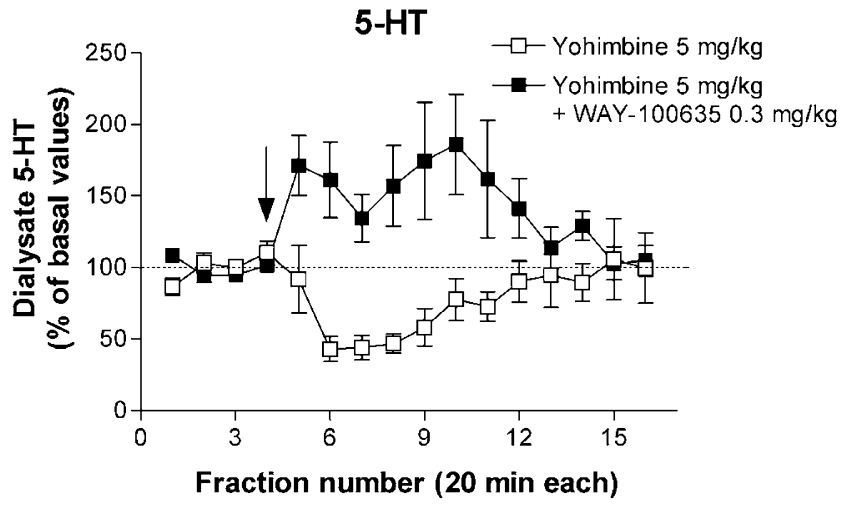

Figure 5 The $\alpha_{2}$-adrenoceptor antagonist yohimbine $(5 \mathrm{mg} / \mathrm{kg}$ i.p.) markedly reduced $5-H T$ output in the DR. This effect was fully counteracted by the selective 5-HT IA receptor antagonist WAY-I00635 $(0.3 \mathrm{mg} / \mathrm{kg}$ s.c.), indicating that the reduction produced by yohimbine was because of nonspecific action at 5-HT IA receptors. Data from 4 rats/group. See results for statistical analysis.

5-HT, with a maximal reduction to $18 \%$ of baseline at $1 \mathrm{mg} /$ $\mathrm{kg}$ (Figure 4b).

The effect of clonidine $(0.1 \mathrm{mg} / \mathrm{kg})$ on $5-\mathrm{HT}$ and NA output in the DR was antagonized by the selective $\alpha_{2}$-adrenoceptor antagonist RX-821002 (1 mg/kg s.c.) $(p<0.000001$ vs clonidine alone for both amines). The latter compound raised by itself the 5-HT and NA output to $185 \pm 16$ and $180 \pm 21 \%$ of baseline, respectively $(p<0.000001 v s$ controls for both amines) (Figures $4 c$ and d). In contrast, the $\alpha_{2}$-adrenoceptor antagonist yohimbine

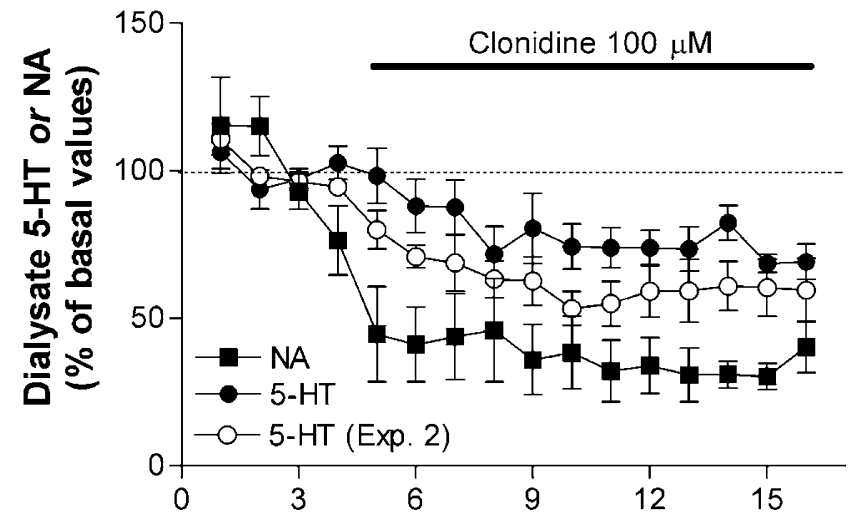

Fraction number (20 min each)

Figure 6 Effect of the local application of $100 \mu \mathrm{M}$ clonidine on the 5-HT and NA output in the DR. The 5-HT data correspond to two different experiments employing two different HPLC methods. Filled symbols (circles, 5-HT; squares, NA, $n=5$ ) are from the same dialysate samples, as in previous figures. The open circles correspond to a second experiment in which the concentration of 5-HT in dialysate samples was determined using a standard HPLC procedure $(n=6)$ (see the Materials and methods section). The $5-H T$ values from both experiments did not significantly differ. Clonidine was notably more effective to reduce the output of NA than that of $5-\mathrm{HT}$

( $5 \mathrm{mg} / \mathrm{kg}$ i.p.) reduced the 5 -HT output to $\sim 45 \%$ of baseline $\left(\mathrm{F}_{15,105}=2.50, \quad p<0.0035\right.$, time effect; $\mathrm{F}_{15,105}=2.45$, $p<0.005$, time $\times$ group interaction) (Figure 5). However, this effect appeared unrelated to an action at $\alpha_{2}$-adrenoceptors because the $5-\mathrm{HT}_{1 \mathrm{~A}}$ receptor antagonist WAY- 
$100635(0.3 \mathrm{mg} / \mathrm{kg}$ s.c. $)$ fully counteracted the yohimbineinduced decrease in 5-HT $\left(\mathrm{F}_{15,90}=3.27, p<0.0025\right.$ vs yohimbine alone) (Figure 5), suggesting that the agonist properties of yohimbine for $5-\mathrm{HT}_{1 \mathrm{~A}}$ receptors were involved (Millan et al, 2000).

The local administration of clonidine $(100 \mu \mathrm{M})$ in the DR reduced maximally the NA output to $30 \pm 5 \%$ of baseline $\left(\mathrm{F}_{1,7}=52.5, \quad p<0.0002\right.$, group effect; $\mathrm{F}_{15,105}=3.8$, $p<0.00002$, time effect; $F_{15,105}=5.5, p<0.00001$, time$\times$ group interaction, Figure 6$)$. However, the effect on the 5 -HT output was more moderate, reaching only a $70-75 \%$ of baseline (Figure 6). A second experiment was carried out in which the local effect of clonidine on 5-HT was assessed using a standard HPLC procedure (eg Adell and Artigas, 1998). The effects of this second experiment are also depicted in Figure 6. A two-way ANOVA analysis did not reveal any significant difference between the data of both experiments, and therefore they were pooled and analyzed together. The effect of local clonidine on the 5-HT output showed a significant effect of time $\left(\mathrm{F}_{15,210}=3.6, p<0.00002\right)$ and the time $\times$ group interaction $\left(\mathrm{F}_{15,210}=1.9, p<0.03\right)$.

\section{Effects of Lesions on the Modulation of the 5-HT Output by $\alpha$-Adrenoceptors}

To examine the possible involvement of $\alpha$-adrenoceptors outside the DR in the control of the 5-HT output, several lesion procedures were carried out in order to eliminate or reduce the putative influence of such receptors on the systemic effects of prazosin and clonidine. Three types of lesions were performed, namely lesions of noradrenergic neurons with the selective neurotoxin DSP-4, electrolytic lesions of the lateral habenula, and cortical transections. Groups of rats were pretreated with the noradrenergic neurotoxin DSP-4 (40 mg/kg i.p., 5 days before experiments). The concentration of 5-HT and NA in the frontal cortex of control rats was $248 \pm 12$ and $332 \pm 17 \mathrm{pmol} / \mathrm{g}$, respectively $(n=10)$. Rats pretreated with DSP-4 showed a very marked reduction of the tissue NA content $(28 \pm 4 \mathrm{pmol} / \mathrm{g}, 11 \%$ of controls, $p<0.00001)$ without a significant change of the 5-HT concentration $(254 \pm 20 \mathrm{pmol} / \mathrm{g} ; n=19)$. Table 1 shows the baseline concentrations of 5-HT and NA in DR dialysates of untreated rats and in those subjected to the various lesion procedures.

Modulation of the Effects of Prazosin Figure 7 shows the local effect of prazosin on the 5-HT and NA output in the DR of previously untreated rats and in rats subjected to the above lesions. Rats lesioned with DSP-4 had significantly lower values of dialysate 5-HT compared with the respective control group $(21.3 \pm 5.4$ vs $39.8 \pm 5.8 \mathrm{fmol} /$ fraction in DSP-4 $(n=10)$ and untreated rats $(n=12)$, respectively; $p<0.03)$. This difference was marginally significant $(p=0.06)$ when considering all untreated rats used in the present study (Table 1). The local administration of prazosin reduced dialysate 5-HT in both groups, although the effect was significantly less marked in DSP-4-lesioned rats $\left(\mathrm{F}_{15,300}=35.71, p<0.000001\right.$, time effect; $\mathrm{F}_{15,300}=6.16$, $p<0.0000001$, time $\times$ group interaction). In neither group prazosin application altered the dialysate NA concentration in the DR (Figure 7).

However, neither DSP-4 pretreatment nor the lesion of the lateral habenula or the cortical transection altered the effect of systemic prazosin $(0.3 \mathrm{mg} / \mathrm{kg}$ s.c.) on the DR $5-\mathrm{HT}$ output in a significant manner $\left(\mathrm{F}_{15,315}=32.7, p<0.000001\right.$, significant effect of time but not of the group or group$\times$ time interaction). The average post-treatment values (fractions 6-16) were $69 \pm 4(n=8), 70 \pm 5(n=6), 76 \pm 4$ $(n=7)$, and $70 \pm 2(n=4)$ for controls, DSP-4-lesioned, lateral habenula-lesioned, and cortically transected rats, respectively (n.s., one-way ANOVA) (Figure 8a). Neither condition altered the inability of prazosin to alter the NA output in the DR (Figure $8 \mathrm{~b}$ ).

Modulation of the Effects of Clonidine The lesion with the noradrenergic neurotoxin DSP-4 significantly attenuated the suppressing effect of local clonidine application $(100 \mu \mathrm{M})$ on dialysate 5-HT $\left(\mathrm{F}_{15,270}=4.89, p<0.000001\right.$, time effect; $F_{15,270}=3.52, p<0.000015$, time $\times$ group interaction) (Figure 9). However, although the effect of the DSP4 lesion attenuated the effect on NA output, the change did not reach statistical significance (Figure 9). These data clearly indicated that the effects of local clonidine on the 5HT release in the DR were dependent on $\alpha_{2}$-adrenoceptors located on noradrenergic elements within the DR.

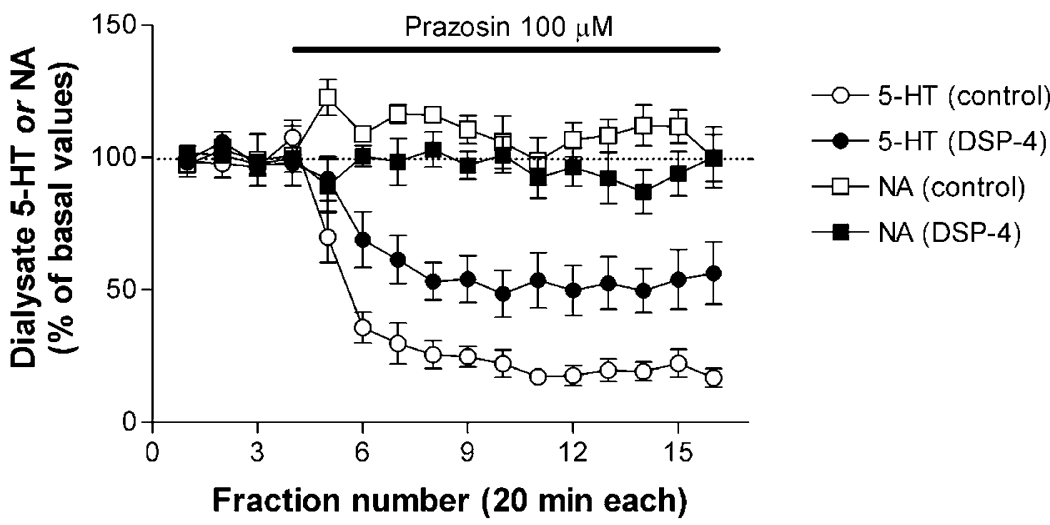

Figure 7 The local application of prazosin $(100 \mu \mathrm{M})$ in the DR of rats lesioned with DSP-4 (40 mg/kg i.p., 5 days before, filled circles, $n=10)$ reduced the 5 -HT output to an extent lesser than in untreated rats (open circles, $n=8$ ). The concentration of NA was unaffected in both instances. See text for statistical analysis. 
a

\section{5-HT}

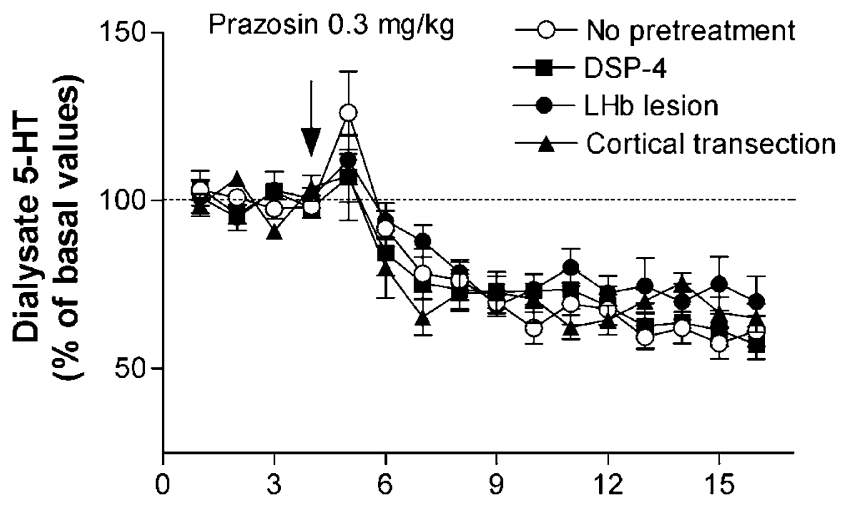

b

NA

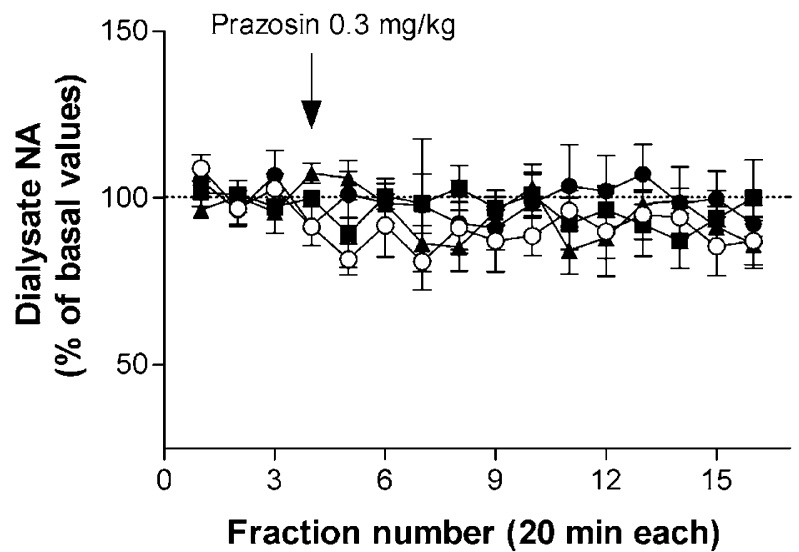

Figure 8 (a) Effect of the s.c. administration of prazosin $(0.3 \mathrm{mg} / \mathrm{kg})$ on 5 HT output in the DR in previously untreated rats (open circles) or in (i) rats pretreated with the noradrenergic neurotoxin DSP-4 (40 mg/kg i.p., 5 days before) (filled squares), (ii) rats with electrolytic lesions of the lateral habenula (LHb, filled circles), and (iii) rats with cortical transection (filled triangles). (b) In all experimental groups, the administration of prazosin left unaltered the NA concentration. Data from 4 to 8 rats/group. See results for statistical analysis.
The lesion with DSP-4 also attenuated the reducing effect of $0.1 \mathrm{mg} / \mathrm{kg}$ clonidine on the DR $5-\mathrm{HT}$ output $\left(\mathrm{F}_{15,180}=4.12, \quad p<0.000002\right.$, time effect; $\mathrm{F}_{15,180}=2.73$, $p<0.0009$, time $\times$ group interaction) (Figure 10a). Likewise, the electrolytic lesion of the lateral habenula attenuated the suppressing effect of $0.1 \mathrm{mg} / \mathrm{kg}$ clonidine on the 5 -HT output $\left(\mathrm{F}_{15,195}=4.85, \quad p<0.000001\right.$, time effect; $\mathrm{F}_{15,195}=4.03, p<0.000002$, time $\times$ group interaction) (Figure 10a). In contrast, the effect of clonidine appeared to be more marked in rats subjected to cortical transection $(n=10)$, although this difference did not reach statistical significance (Figure 10a). The DSP-4 lesion attenuated the effect of clonidine $0.1 \mathrm{mg} / \mathrm{kg}$ s.c. on the NA output in the DR $\left(\mathrm{F}_{15,180}=15.57, p<0.000001\right.$, time effect; $\mathrm{F}_{15,180}=4.01$, $p<0.000003$, time $\times$ group interaction) while the lesion of the lateral habenula or the cortical transection did not alter the effect of clonidine on NA output (Figure 10b).

Overall, the above data suggested that the suppressant effect of clonidine on 5-HT release in the DR was because of different subsets of $\alpha_{2}$-adrenoceptors, located, respectively, in the DR and elsewhere in the brain, likely in forebrain regions that control serotonergic activity indirectly, through the habenulo-raphe pathway (Aghajanian and Wang, 1977). The activity of 5-HT neurons is modulated, among others, by local GABAergic afferents whose inhibitory inputs appear to vary with anesthesia (Tao and Auerbach, 1994; Jolas and Aghajanian, 1997). Hence, we next examined the effect of clonidine on the 5-HT and NA output of chloral hydrate anesthetized rats. These were subjected to the usual experimental procedures (see the Materials and methods section), but the entire experiments were performed under chloral anesthesia $(400 \mathrm{mg} / \mathrm{kg}$ i.p. followed by supplemental doses). In chloral hydrate anesthetized rats $(n=7)$, clonidine increased the 5-HT output, a change that was significantly different from that seen in unanesthetized rats $\left(\mathrm{F}_{1,13}=5.70, \quad p<0.035\right.$, group effect; $\mathrm{F}_{15,195}=8.87$, $p<0.000001$, group $\times$ time interaction) (Figure 11a). In contrast, the effect of clonidine on the NA output did not differ between awake and anesthetized rats.

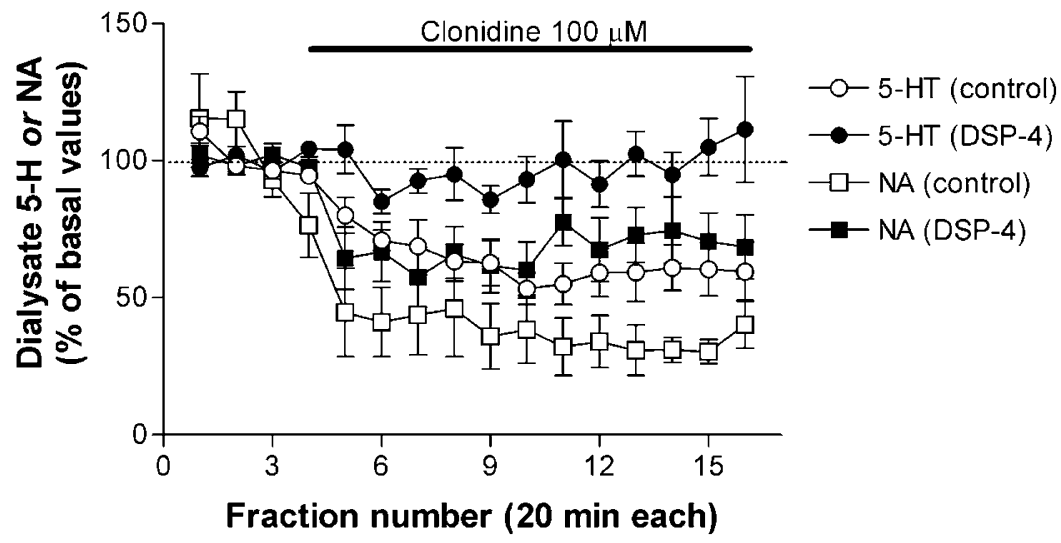

Figure 9 The suppressant effect of local clonidine administration on 5-HT release in the DR was virtually abolished by the pretreatment with DSP-4 ( $40 \mathrm{mg} / \mathrm{kg}$ i.p., 5 days before, filled circles). DSP-4 pretreatment also attenuated the effect of clonidine on NA output, but this effect did not reach statistical significance. Data from 5 to $1 \mathrm{I}$ rats/group. See text for detailed statistical analysis. 
a

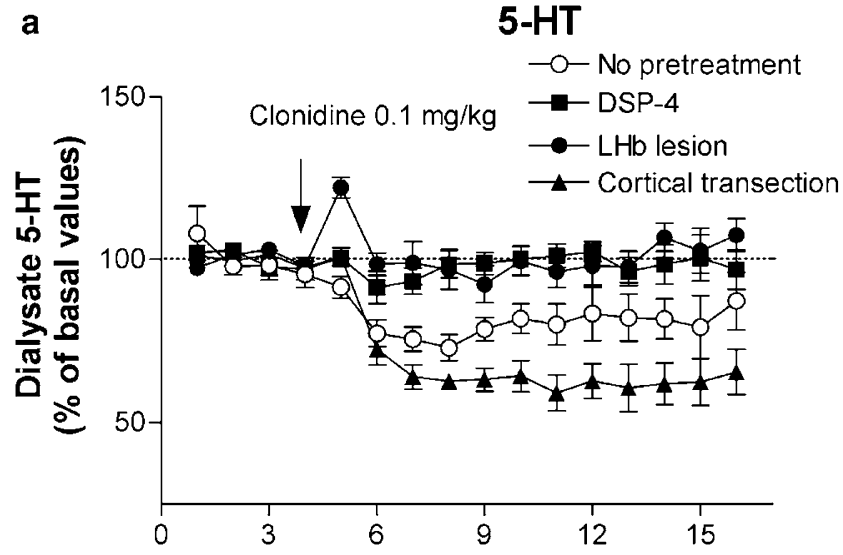

b

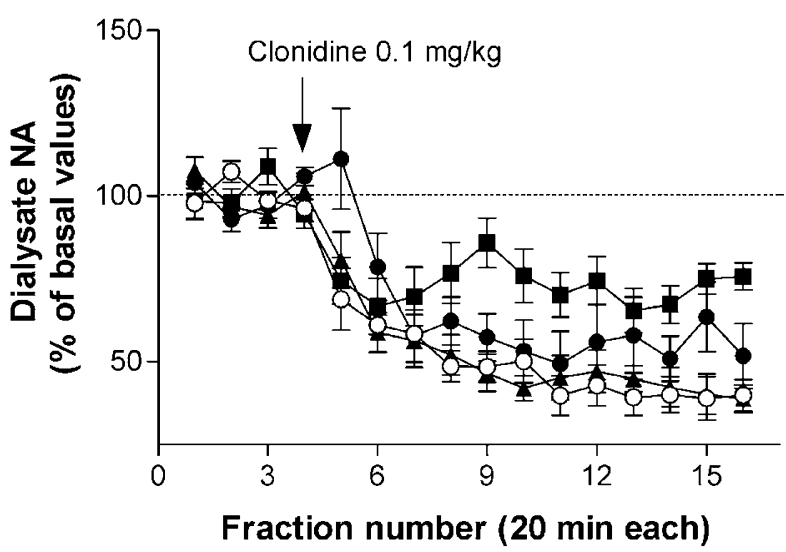

Figure 10 (a) Effect of the s.c. administration of clonidine $(0.1 \mathrm{mg} / \mathrm{kg})$ on 5-HT output in the DR in previously untreated rats (open circles) or in (i) rats pretreated with the noradrenergic neurotoxin DSP-4 (40 mg/ $/ \mathrm{kg}$ i.p., 5 days before) (filled squares), (ii) rats with electrolytic lesions of the lateral habenula ( $\mathrm{LHb}$; filled circles), and (iii) rats with cortical transection (filled triangles). The first two lesion procedures abolished the effects of clonidine on 5-HT output, whereas the cortical transection exhibited a tendency towards a greater 5-HT reduction, but this difference did not reach statistical significance. (b) The effect of clonidine on NA output was only moderately, but significantly, affected by the DSP-4 lesion. Data from 6 to 10 rats/group. See results for statistical analysis.

\section{DISCUSSION}

Previous work by our group showed that the in vivo release of 5-HT in the median raphe nucleus is under the control of $\alpha_{1}$ - and $\alpha_{2}$-adrenoceptors in this nucleus (Adell and Artigas, 1999). Similarly, microdialysis studies in rat forebrain revealed that the 5 -HT release is also regulated by both families of $\alpha$-adrenoceptors (Tao and Hjorth, 1992; Rouquier et al, 1994; Bel and Artigas, 1996; Gobert et al, 1998). Here we extend these previous observations to the control of the 5-HT release in the DR using both local and systemic administration of $\alpha$-adrenoceptor ligands.

\section{Methodological Aspects}

The HPLC method employed in this study enabled one to determine simultaneously the concentration of $5-\mathrm{HT}$ and NA in brain dialysates. As in previous studies from this and other groups, citalopram was added to the perfusion fluid.
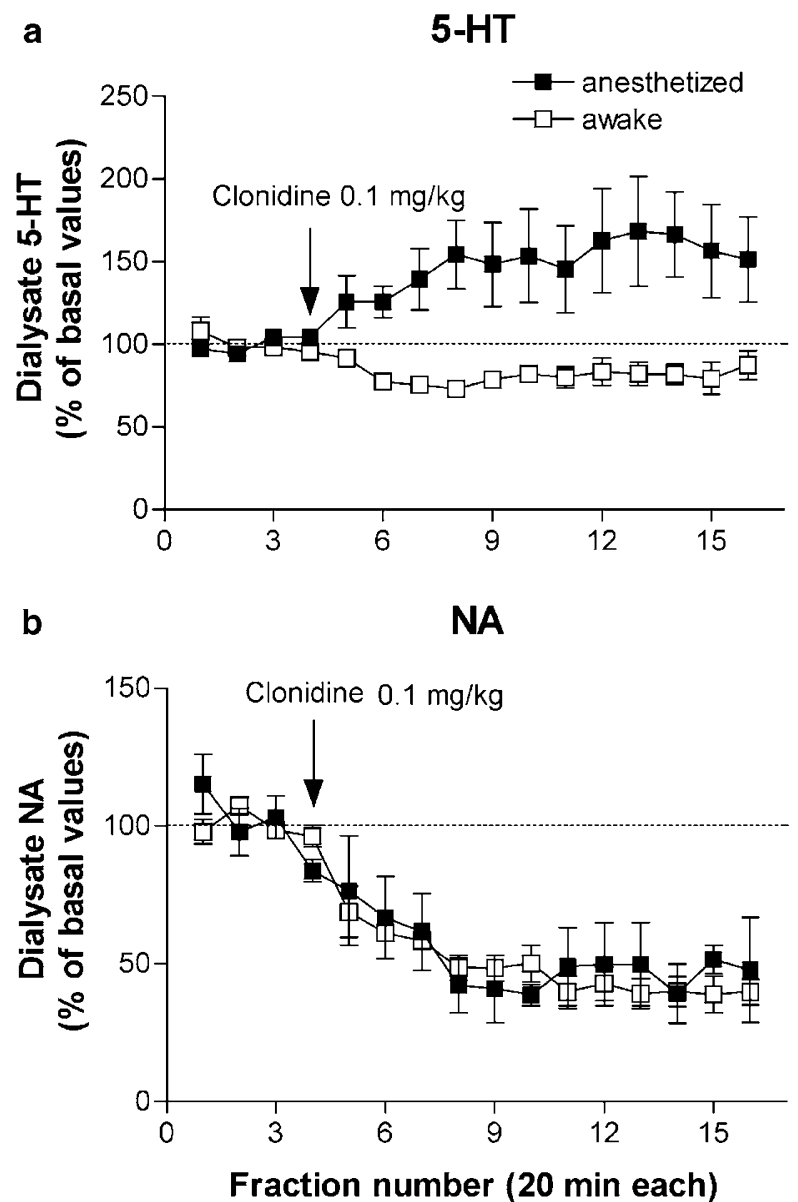

Figure II (a) In rats anesthetized with chloral hydrate before microdialysis experiments, the systemic administration of clonidine (0.I mg/kg s.c.) increased 5-HT output in the DR (filled squares). (b) The effect of clonidine on NA output was unaltered by the previous anesthesia. Data from 4 to 8 rats/group. See text for statistical analysis.

This aspect was deemed essential for the success of the study given that (a) 5-HT eluted at a long retention time (with the consequent reduction in peak height), (b) most treatments used were expected to markedly reduce $5-\mathrm{HT}$ release, and (c) the success of fundamental parts of the study (eg dose-response experiments, effects of lesions) relied on an accurate discrimination among the $5-\mathrm{HT}$ values in the various experimental groups. Although 5- $\mathrm{HT}_{1 \mathrm{~A}}$ autoreceptors control 5-HT release in the DR, the concern on a potential interference of the action of citalopram with those of the $\alpha$-adrenoceptor agents used appears unwarranted, in view of the following reasons. First, citalopram $1 \mu \mathrm{M}$ inhibits partially 5-HT reuptake (Hervás et al, 2000) and causes little activation of $5-\mathrm{HT}_{1 \mathrm{~A}}$ receptors (Tao et al, 2000). Higher concentrations (typically $>10 \mu \mathrm{M}$ ) are required to activate significantly $5-\mathrm{HT}_{1 \mathrm{~A}}$ receptors and to reduce 5-HT release (Romero et al, 1994; Tao et al, 2000). Indeed, despite the large nominal concentrations, the amount of drugs applied by reverse dialysis at low perfusion rates is small and the extent of diffusion is very limited (eg WAY-100635; Celada et al, 2001). Second, $1 \mu \mathrm{M}$ citalopram did not interfere with the local or systemic actions of 5$\mathrm{HT}_{1 \mathrm{~A}}$ receptor ligands on 5-HT release in the midbrain or forebrain (Casanovas and Artigas, 1996; Adell and Artigas, 
1998; Casanovas et al, 1999). Finally, the 5-HT reduction effected by $0.3 \mathrm{mg} / \mathrm{kg}$ prazosin in the presence and absence of citalopram did not differ.

Overall, these data illustrate that in the experimental conditions used, dialysate 5-HT and NA concentrations are representative of a neuronal, impulse-dependent release in the DR. 5-HT may arise from dendrites but also from the initial segments of the branching axons, since the DR contains a dense network of 5-HT efferent fibers (Steinbusch, 1981; Halliday et al, 1995) whereas dialysate NA likely originates from the dense plexus of noradrenergic fibers in the DR (see below). These may release NA in an impulse-dependent manner, as observed in the forebrain (L'Heureux et al, 1986). Likewise, most previous reports support the notion that the 5 -HT release in the DR varies in parallel with serotonergic activity (Casanovas and Artigas, 1996, Casanovas et al, 1997; Matos et al, 1996; Celada et al, 2001). As previously reported in the hippocampus of awake rats (Done and Sharp, 1994), 8-OH-DPAT increased NA release in the DR.

\section{Modulation of 5-HT Release by $\alpha$-Adrenoceptors}

The DR receives a dense noradrenergic innervation from the pontine noradrenergic cell groups (Sakai et al, 1977; Baraban and Aghajanian, 1980; Peyron et al, 1996). Neurochemical studies have revealed the presence of noradrenaline and NA uptake sites in the DR (Saavedra et al, 1976; Tejani-Butt, 1992; Ordway et al, 1997; Strazielle et $a l, 1999)$. Autoradiographic, immunohistochemical, and in situ hybridization studies show an abundance of $\alpha_{1}$ adrenoceptors in the DR, whereas the presence of $\alpha_{2}$ adrenoceptors is not accompanied by their encoding mRNA (Unnerstall et al, 1984; Pieribone et al, 1994; Nicholas et al, 1996; Rosin et al, 1996; Talley et al, 1996; Day et al, 1997; Winzer-Serhan et al, 1997a, b). Early studies indicated that the activity of 5-HT neurons in the DR is under an excitatory control by $\alpha_{1}$-adrenoceptors (Baraban and Aghajanian, 1980; VanderMaelen and Aghajanian, 1983). In agreement, the $\alpha_{1}$-adrenoceptor agonist phenylephrine depolarized DR 5-HT neurons in vitro, an effect blocked by prazosin (Pan et al, 1994). This, together with the distribution of cells expressing $\alpha_{1 \mathrm{~B}}$-adrenoceptors in the DR (Pieribone et al, 1994; Day et al, 1997), suggests that $\alpha_{1-}$ adrenoceptors are located on 5-HT neurons. However, to the best of our knowledge, no detailed histological studies (ie double immunohistochemical or in situ hybridization) have been performed to fully confirm this view.

Likewise, the DR also contains a moderate density of $\alpha_{2}$ adrenoceptors, as assessed by autoradiography (eg with $\left[{ }^{3} \mathrm{H}\right]$ para-aminoclonidine; Unnerstall et al, 1984). Immunohistochemical studies also show the presence of $\alpha_{2 \mathrm{~A}^{-}}$and $\alpha_{2 \mathrm{C}}$-adrenoceptor immunoreactivity in the DR (Rosin et al, 1996; Talley et al, 1996). However, in situ hybridization studies failed to reveal a significant density of the mRNAs encoding $\alpha_{2 \mathrm{~A}^{-}}$and $\alpha_{2 \mathrm{C}^{-}}$-adrenoceptors in the DR (McCune et al, 1993; Nicholas et al, 1993, 1996; Scheinin et al, 1994). This suggests that the majority of $\alpha_{2}$-adrenoceptors in the DR are located in noradrenergic terminals where they function as autoreceptors and control the release of NA.

The local and systemic administration of the $\alpha_{1}$-adrenoceptor antagonist prazosin reduced the 5-HT release in the
DR. Local prazosin $(100 \mu \mathrm{M})$ virtually suppressed the 5-HT release, without affecting that of NA. This effect was similar in magnitude to that of treatments that fully suppress serotonergic activity, such as TTX or $5-\mathrm{HT}_{1 \mathrm{~A}}$ agonists, which emphasizes the importance of the noradrenergic input onto 5-HT neurons for their normal function. However, it is unclear whether the $\alpha_{1}$-adrenergic tone in the DR can be further enhanced. Pilot experiments with phenylephrine $(100 \mu \mathrm{M}$ in the DR) did not enhance the 5HT output (Celada and Artigas, 1993). Given the low intrinsic efficacy of phenylephrine and the possibility of nonspecific actions of cirazoline (Ruffolo and Waddell, 1982 ), in the present study we sought to further enhance the tone on $\alpha_{1}$-adrenoceptors with the endogenous transmitter. To this end, we applied a combination of NA and desipramine (to prevent its reuptake by noradrenergic terminals). The inability of this procedure to elevate 5-HT release suggests that the tone on $\alpha_{1}$-adrenoceptors is already maximal in the present experimental conditions, although we cannot fully exclude that the $\alpha_{1}$-adrenoceptor-blocking properties of desipramine may have partly attenuated a potential NA-induced increase in 5-HT output. Previous data from this laboratory suggest that the 5-HT output in the MnR may be further enhanced by cirazoline (Adell and Artigas, 1999). This would indicate a different regulation of DR and MnR neurons by $\alpha_{1}$-adrenoceptors, a view also supported by the greater reduction in hippocampal 5-HT release (compared with striatal 5-HT release) after systemic prazosin administration (Rouquier et al, 1994). However, in view of the above limitations, a strict regional comparison of the effect of $\alpha_{1}$-adrenoceptor stimulation in DR and MnR is still lacking. Intriguingly, bath addition of phenylephrine reduced the stimulated 5-HT release in midbrain slices containing the DR, as assessed by voltammetry (Hopwood and Stamford, 2001). This observation, at variance with the widely accepted stimulatory role of $\alpha_{1}$-adrenoceptors in the DR (Vandermaelen and Aghajanian, 1983; Pan et al, 1994), may result from the particular experimental conditions used (deafferented midbrain slices, high stimulation rates) (Hopwood and Stamford, 2001).

The inability of the desipramine+NA combination to increase the 5-HT output in the DR may seem discordant with the enhancement of 5-HT release produced by the systemic administration of RX-821002. This agent could conceivably enhance serotonergic transmission through the removal of a self-inhibitory effect of NA on noradrenergic terminals in the DR, thus increasing the release of NA (Figure $4 \mathrm{~d}$ ) and hence the tone on postsynaptic $\alpha_{1^{-}}$ adrenoceptors. Indeed, the systemic and intra-raphe administration of idazoxan, another $\alpha_{2}$-adrenoceptor antagonist, increased the firing rate of 5-HT neurons in the DR (Garratt et al, 1991; Hertel et al, 1997). Although this possibility cannot be fully discarded, it seems unlikely in view of the different temporal profile of 5-HT and NA changes after systemic RX 821002 administration (Figures $4 \mathrm{c}$ and d). Moreover, RX 821002 is also a $5-\mathrm{HT}_{1 \mathrm{~A}}$ antagonist (Newman-Tancredi et al, 1998) and could thus contribute to increase 5-HT release in the DR, as observed with WAY 100635 (Martín-Ruiz et al, 2001b). Given that $\alpha_{2}$-adrenoceptors outside the DR also control 5-HT release (see below), it would be possible that RX 821002 enhanced 5-HT release by an action at such extra-raphe receptors. 
Interestingly, the reduction of 5-HT release elicited by the local application of prazosin was more marked than by its systemic administration (0.3-3 mg/kg s.c.). The comparable effects of 0.3 and $1 \mathrm{mg} / \mathrm{kg}$ suggest that this was a nearly maximal effect, whereas $3 \mathrm{mg} / \mathrm{kg}$ appeared to be less effective. Interestingly, a similar dose range $(0.1-1 \mathrm{mg} / \mathrm{kg}$ s.c.) reduced dose-dependently the 5 -HT output in ventral hippocampus to a maximum of $30 \%$ of baseline (Hjorth et al, 1995). Lower i.v. doses $(0.03-0.4 \mathrm{mg} / \mathrm{kg})$ also induced a marked reduction of hippocampal 5-HT output (Rouquier et al, 1994). The local-systemic difference in the present study cannot be ascribed to an unusually marked effect of the local application, since two different experiments performed several months apart gave identical results. Thus, the possibility exists that prazosin may additionally modulate DR serotonergic activity and 5-HT release by $\alpha_{1}$ adrenoceptors outside the DR, whose blockade would oppose that in the DR, thus resulting in an attenuated effectiveness of the systemic administration.

The lateral habenula and the medial prefrontal cortex are two forebrain structures that densely innervate the DR and control the activity of 5-HT neurons in this nucleus (Aghajanian and Wang, 1977; Stern et al, 1981; Sesack et al, 1989; Takagishi and Chiba, 1991; Hajós et al, 1998; Peyron et al, 1998; Celada et al, 2001; Martín-Ruiz et al, 2001a). The density of the various $\alpha$-adrenoceptor subtypes in the lateral habenula ranges from none to moderate (Unnerstall et al, 1984; Pieribone et al, 1994; Rosin et al, 1996; Day et al, 1997; Winzer-Serhan et al, 1997a,b). However, several areas rich in $\alpha_{1}$ - and $\alpha_{2}$-adrenoceptors projecting to the lateral habenula, such as the hippocampus or the amygdala (Matthews-Felton et al, 1999), contain a high density of both $\alpha$-adrenoceptor families. Likewise, all cortical layers in the frontal cortex contain a moderate to high density of $\alpha$-adrenoceptors (Unnerstall et al, 1984; Pieribone et al, 1994; Rosin et al, 1996; Day et al, 1997; Winzer-Serhan et al, 1997a,b) that could be involved in the distal control of serotonergic activity and 5-HT release, as shown for cortical (prefrontal) $5-\mathrm{HT}_{1 \mathrm{~A}}$ and 5$\mathrm{HT}_{2 \mathrm{~A}}$ receptors (Ceci et al, 1994; Hajós et al, 1999; Celada et al, 2001; Martín-Ruiz et al, 2001a; Martín-Ruiz and Ugedo, 2001). Likewise, the medial prefrontal cortex controls the activity of locus coeruleus noradrenergic neurons (Jodo et al, 1998), which in turn might affect 5 -HT neurons in the DR.

To examine the influence of such distal influences, we performed lesion experiments, that is, bilateral electrolytic lesions of the lateral habenula and cortical transections. Furthermore, groups of rats were treated with the selective noradrenergic neurotoxin DSP-4 to assess whether the effects of clonidine and prazosin were dependent on the noradrenergic input onto DR 5-HT neurons.

Contrary to our initial assumption, neither the cortical transection nor the electrolytic lesion of the lateral habenula significantly modified the suppressant effects of $0.3 \mathrm{mg} / \mathrm{kg}$ prazosin on 5-HT release in the DR. The lesion with DSP-4 attenuated the suppressant effect of the local (but not systemic) prazosin administration. The lower effect of local prazosin in DSP-4-treated rats may reflect a diminished tone on $\alpha_{1}$-adrenoceptors on 5-HT neurons (ie resulting from damaged noradrenergic terminals) or be the result of adaptive pre- and postsynaptic mechanisms secondary to the loss of noradrenergic fibers. In support of the latter possibility is the observation that the NA output in the DR was increased in DSP-4-lesioned rats, perhaps as a compensatory mechanism to the massive loss of tissue NA and noradrenergic terminals. A lack of reduction of NA release after DSP-4 treatment has also been reported in rat frontal cortex (Kask et al, 1997).

The similar reduction elicited by $0.3 \mathrm{mg} / \mathrm{kg}$ prazosin in untreated and DSP-4 lesioned rats suggests that the blockade of $\alpha_{1}$-adrenoceptors in the DR produced by this systemic dose is lower than that produced by its local application and/or that different receptor populations are being affected by both procedures. The inherent complexity of in vivo microdialysis prevented the realization of a full dose-response study after these lesion procedures. Hence, it cannot be discarded that the above lesions might alter the effect of higher doses of prazosin (eg $3 \mathrm{mg} / \mathrm{kg}$ ) that appeared to elicit an abnormally low effect on 5-HT release.

The local and systemic administration of clonidine reduced the in vivo 5-HT release in the DR, as previously observed in the MnR and forebrain areas (Tao and Hjorth, 1992; Bel and Artigas, 1996; Adell and Artigas, 1999). The clonidine-induced 5-HT reductions (local and systemic) were more moderate than those elicited by prazosin, maybe because of the partial agonist properties of clonidine. Unlike prazosin, systemic clonidine reduced 5-HT release more than its local application. The local effect possibly involves the activation of $\alpha_{2}$-adrenoceptors on noradrenergic terminals that synapse on and activate 5-HT neurons through $\alpha_{1}$ adrenoceptors. The systemic action of clonidine likely involves also somatodendritic $\alpha_{2}$-autoreceptors in the pontine nuclei, whose activation should result in the observed reduction of NA release, and hence of the tone on postsynaptic $\alpha_{1}$-adrenoceptors on 5-HT neurons. Additionally, clonidine might reduce 5-HT release in the DR via the activation of $\alpha_{2}$-heteroceptors on 5-HT axonal varicosities within this nucleus. This mechanism has been assumed to underlie in part the action of clonidine on the 5HT system in forebrain (Tao and Hjorth, 1992; Bel and Artigas, 1996; Mongeau et al, 1997) and DR (Hopwood and Stamford, 2001). However, the lesion with DSP-4 virtually abolished the effects of local clonidine on 5-HT release, which suggests that, when applied in the DR, it acts predominantly on $\alpha_{2}$-autoreceptors. Likewise, the effect of the systemic administration of clonidine on 5-HT release depends, among other factors, on the integrity of NA neurons (ie somatodendritic and terminal $\alpha_{1}$-adrenoceptors) as it was also cancelled by the previous lesion with DSP-4. However, because the DR contains a dense network of 5-HT fibers, $\alpha_{2}$-heteroceptors might also contribute, as suggested by voltammetric studies (Hopwood and Stamford, 2001).

The effect of systemic clonidine administration on 5-HT (but not NA) release was also cancelled by the lesion of the lateral habenula and appeared to be more marked (although not significantly) in rats subjected to cortical transection. In a small number of rats, the lesion of the lateral habenula with kainic acid also abolished the effect of clonidine on 5HT release (unpublished observations). These rats also had a massive loss of hippocampal tissue, as a result of the proximity of the injection site and the sensitivity of hippocampal neurons to kainic acid. Moreover, clonidine 
increased 5-HT (but not NA) release in rats anesthetized with chloral hydrate, suggesting that in this condition the effect of clonidine on 5-HT release opposed that produced through the activation of $\alpha_{2}$-adrenoceptors on noradrenergic neurons. The effect of anesthesia may be because of a putative change of inhibitory inputs onto 5-HT neurons, as observed with morphine and baclofen, two drugs affecting 5-HT release in the DR via GABAergic interneurons (Tao and Auerbach, 1994; Jolas and Aghajanian, 1997; Abellan et $a l, 2000)$. Thus, the chloral hydrate-induced prevention of the effect of clonidine possibly reflects the existence of $\alpha_{2}$ adrenoceptors in areas that project to 5-HT neurons in the DR via GABAergic afferents or local interneurons. Indeed, early observations in chloral hydrate anesthetized rats already suggested a complex action of clonidine on 5-HT neurons. Thus, low i.v. doses reduced the firing rate of 5-HT neurons, yet this effect disappeared at higher doses (Svensson et al, 1975). Moreover, although bath application of NA excites and clonidine inhibits 5-HT neurons in the slice preparation (Alojado et al, 1994) the microiontophoretic application of clonidine in the DR did not suppress the firing of 5-HT neurons (Dresse and Scuvee-Moreau, 1986). Our results give support to the notion that the action of clonidine on $5-\mathrm{HT}$ release is indirect. In the DR, $\alpha_{2}$ adrenoceptors responsible for this effect appear to be located on noradrenergic terminals, although $\alpha_{2}$-heteroceptors may also participate (Hopwood and Stamford, 2001). Moreover, based on lesion studies and the interaction of anesthesia with the effect of clonidine on 5-HT release, we propose the involvement of $\alpha_{2}$-adrenoceptors on other brain areas, although we cannot clarify which of the various candidate forebrain structures is involved. Interestingly, neither lesion procedure nor anesthesia (with the exception of DSP-4, discussed above) altered the effect of clonidine on NA output, which supports a direct action of clonidine on NA neurons and emphasizes the indirect nature of the effect on 5-HT neurons.

In summary, the present results support the notion that the 5 -HT release in the DR is strongly dependent on the activation of $\alpha_{1}$-adrenoceptors in this nucleus. The tone on such receptors appears to be maximal in the experimental conditions used (daylight, unanesthetized rats). Likewise, the activation of $\alpha_{2}$-adrenoceptors in the DR reduces the release of 5-HT, although to a lesser extent than the blockade of $\alpha_{1}$-adrenoceptors. This effect is predominantly mediated by $\alpha_{2}$-autoreceptors located on noradrenergic terminals, since it is dependent on the integrity of noradrenergic neurons. Finally, based on the discrepancies between the local and systemic effects of prazosin and clonidine and on the results of lesion studies, we suggest that $\alpha$-adrenoreceptors outside the DR are involved in the control of 5-HT release in the DR as well.

\section{ACKNOWLEDGMENTS}

This work was supported by grants from the Ministry of Science and Technology and Ministry of Health (SAF 20012133 and Fis 2001-1147). The authors wish to acknowledge the skilful technical assistance of Leticia Campa in the HPLC analyses. A.B. is recipient of a postdoctoral fellowship (MAE, Fundación Carolina).

\section{REFERENCES}

Abellan MT, Jolas T, Aghajanian GK, Artigas F (2000). Dual control of dorsal raphe serotonergic neurons by GABA(B) receptors. Electrophysiological and microdialysis studies. Synapse 36: 2134.

Adell A, Artigas F (1998). A microdialysis study of the in vivo release of 5-HT in the median raphe nucleus of the rat. $\mathrm{Br} J$ Pharmacol 125: 1361-1367.

Adell A, Artigas F (1999). Regulation of the release of 5hydroxytryptamine in the median raphe nucleus of the rat by catecholaminergic afferents. Eur J Neurosci 11: 2305-2311.

Adell A, Sarna GS, Hutson PH, Curzon G (1989). An in vivo dialysis and behavioural study of the release of 5 -HT by $p$ chloroamphetamine in reserpine-treated rats. $\mathrm{Br}$ J Pharmacol 97: 206-212.

Aghajanian GK, Wang RY (1977). Habenular and other midbrain raphe afferents demonstrated by a modified retrograde tracing technique. Brain Res 122: 229-242.

Alojado ME, Ohta Y, Kemmotsu O (1994). The effect of clonidine on the activity of neurons in the rat dorsal raphe nucleus in vitro. Anesth Analg 79: 257-260.

Aston-Jones G, Shipley MT, Chouvet G, Ennis M, van Bockstaele E, Pieribone $\mathrm{V}$ et al (1991). Afferent regulation of locus coeruleus neurons: anatomy, physiology and pharmacology. Prog Brain Res 88: 47-75.

Baraban JM, Aghajanian GK (1980). Suppression of firing activity of 5-HT neurons in the dorsal raphe by alpha-adrenoceptor antagonists. Neuropharmacology 19: 355-363.

Bel N, Artigas F (1996). In vivo effects of the simultaneous blockade of serotonin and norepinephrine transporters on serotonergic function. Microdialysis studies. J Pharmacol Exp Ther 278: 1064-1072.

Blier P, de Montigny C (1987). Modification of 5-HT neuron properties by sustained administration of the $5-\mathrm{HT}_{1 \mathrm{~A}}$ agonist gepirone: electrophysiological studies in the rat brain. Synapse 1: 470-480.

Casanovas JM, Artigas F (1996). Differential effects of ipsapirone on 5-hydroxytryptamine release in the dorsal and median raphe neuronal pathways. J Neurochem 67: 1945-1952.

Casanovas JM, Lésourd M, Artigas F (1997). The effect of the selective $5-\mathrm{HT}_{1 \mathrm{~A}}$ agonists alnespirone (S-20499) and 8-OHDPAT on extracellular 5-hydroxytryptamine in different regions of rat brain. Br J Pharmacol 122: 733-741.

Casanovas JM, Hervas I, Artigas F (1999). Postsynaptic 5- $\mathrm{HT}_{1 \mathrm{~A}}$ receptors control 5-HT release in the rat medial prefrontal cortex. Neuroreport 10: 1441-1445.

Ceci A, Baschirotto A, Borsini F (1994). The inhibitory effect of 8$\mathrm{OH}-\mathrm{DPAT}$ on the firing activity of dorsal raphe serotoninergic neurons in rats is attenuated by lesion of the frontal cortex. Neuropharmacology 33: 709-713.

Celada P, Artigas F (1993). Interaction between noradrenaline and serotonin: unchanged somatodendritic release of serotonin after noradrenergic agonist. Eur J Neurosci 6(Suppl): 168.

Celada P, Puig MV, Casanovas JM, Guillazo G, Artigas F (2001). Control of dorsal raphe serotonergic neurons by the medial prefrontal cortex: involvement of serotonin-1A, GABA(A), and glutamate receptors. J Neurosci 21: 9917-9929.

Dahlström A, Fuxe K (1964). Localization of monoamines in the lower brain stem. Experientia 20: 398-399.

Danish University Antidrepressant Group (1986). Citalopram: clinical effect profile in comparison with clomipramine. A controlled multicenter study. Psychopharmacology 90: 131-138.

Danish University Antidrepressant Group (1990). Paroxetine: a selective serotonin reuptake inhibitor showing better tolerance, but weaker antidepressant effect than clomipramine in a controlled multicenter study. J Affect Disorder 18: 289-299. 
Day HE, Campeau S, Watson Jr SJ, Akil H (1997). Distribution of alpha-1A, alpha-1B and alpha-1D-adrenergic receptor mRNA in the rat brain and spinal cord. J Chem Neuroanat 13: $115-139$.

Done CJ, Sharp T (1994). Biochemical evidence for the regulation of central noradrenergic activity by $5-\mathrm{HT}_{1 \mathrm{~A}}$ and $5-\mathrm{HT}_{2}$ receptors: microdialysis studies in the awake and anaesthetized rat. Neuropharmacology 33: 411-421.

Dresse A, Scuvee-Moreau J (1986). Influence of the alpha-2 agonist oxaminozoline (S3341) on firing rate of central noradrenergic and serotonergic neurons in the rat. Comparison with clonidine. Arch Int Physiol Biochim 94: 99-106.

Garratt JC, Crespi F, Mason R, Marsden CA (1991). Effects of idazoxan on dorsal raphe 5-hydroxytryptamine neuronal function. Eur J Pharmacol 193: 87-93.

Gobert A, Rivet JM, Audinot V, Newman-Tancredi A, Cistarelli L, Millan MJ (1998). Simultaneous quantification of serotonin, dopamine and noradrenaline levels in single frontal cortex dialysates of freely-moving rats reveals a complex pattern of reciprocal auto- and heteroreceptor-mediated control of release. Neuroscience 84: 413-429.

Hajós M, Hajós-Korcsok E, Sharp T (1999). Role of the medial prefrontal cortex in 5-HT1A receptor-induced inhibition of 5HT neuronal activity in the rat. Br J Pharmacol 126: 1741-1750.

Hajós M, Richards CD, Szekely AD, Sharp T (1998). An electrophysiological and neuroanatomical study of the medial prefrontal cortical projection to the midbrain raphe nuclei in the rat. Neuroscience 87: 95-108.

Halliday G, Harding A, Paxinos G (1995). Serotonin and tachiykinin systems. In Paxinos G (ed). The Rat Nervous System, 2nd ed. Academic Press: San Diego. pp 929-974.

Heal DJ, Cheetham SC (1997). SSRIs: where now, where next?In Stanford SC (ed). Selective Serotonin Reuptake Inhibitors. RG Landes Co: Austin, Texas. pp 187-218.

Hertel P, Nomikos GG, Svensson TH (1997). Risperidone inhibits 5-hydroxytryptaminergic neuronal activity in the dorsal raphe nucleus by local release of 5-hydroxytryptamine. Br J Pharmacol 122: 1639-1646.

Hervás I, Queiroz CM, Adell A, Artigas F (2000). Role of uptake inhibition and autoreceptor activation in the control of 5-HT release in the frontal cortex and dorsal hippocampus of the rat. Br J Pharmacol 130: 160-166.

Hjorth S, Bengtsson HJ, Milano S, Lundberg JF, Sharp T (1995). Studies on the role of $5-\mathrm{HT}_{1 \mathrm{~A}}$ autoreceptors and alpha 1adrenoceptors in the inhibition of 5-HT release-I. BMY7378 and prazosin. Neuropharmacology 34: 615-620.

Hopwood SE, Stamford JA (2001). Noradrenergic modulation of serotonin release in rat dorsal and median raphe nuclei via alpha(1) and alpha(2A) adrenoceptors. Neuropharmacology 41: 433-442.

Jacobs BL, Azmitia EC (1992). Structure and function of the brain serotonin system. Physiol Rev 72: 165-229.

Jodo E, Chiang C, Aston-Jones G (1998). Potent excitatory influence of prefrontal cortex activity on noradrenergic locus coeruleus neurons. Neuroscience 83: 63-79.

Jolas T, Aghajanian GK (1997). Opioids suppress spontaneous and NMDA-induced inhibitory postsynaptic currents in the dorsal raphe nucleus of the rat in vitro. Brain Res 755: 229-245.

Kask A, Harro J, Tuomaine P, Rago L, Mannisto PT (1997). Overflow of noradrenaline and dopamine in frontal cortex after [ $\mathrm{N}$-(2-chloroethyl)- $\mathrm{N}$-ethyl-2-bromobenzylamine] (DSP-4) treatment: in vivo microdialysis study in anaesthetized rats. Naunyn Schmiedebergs Arch Pharmacol 355: 267-272.

L'Heureux R, Dennis T, Curet O, Scatton B (1986). Measurement of endogenous noradrenaline release in the rat cerebral cortex in vivo by transcortical dialysis: effects of drugs affecting noradrenergic transmission. J Neurochem 46: 1794-1801.
Martín-Ruiz R, Puig MV, Celada P, Shapiro DA, Roth BL, Mengod $\mathrm{G}$ et al (2001a). Control of serotonergic function in medial prefrontal cortex by serotonin-2A receptors through a glutamate-dependent mechanism. J Neurosci 21: 9856-9866.

Martín-Ruiz R, Ugedo L (2001). Electrophysiological evidence for postsynaptic 5-HT(1A) receptor control of dorsal raphe 5-HT neurones. Neuropharmacology 41: 72-78.

Martin-Ruiz R, Ugedo L, Honrubia MA, Mengod G, Artigas F (2001b). Control of serotonergic neurons in rat brain by dopaminergic receptors outside the dorsal raphe nucleus. $J$ Neurochem 77: 762-775.

Matos FF, Urban C, Yocca, FD (1996). Serotonin (5-HT) release in the dorsal raphe and ventral hippocampus: raphe control of somatodendritic and terminal 5-HT release. J Neural Transm 103: $173-190$.

Matthews-Felton T, Linon L, Rosenblatt JS, Morrell JI (1999). First and second order maternal behavior related afferents to the lateral habenula. Neuroreport 19: 883-887.

McCune SK, Voigt MM, Hill JM (1993). Expression of multiple alpha adrenergic receptor subtype messenger RNAs in the adult rat brain. Neuroscience 57: 143-151.

Meltzer HY (1999). The role of serotonin in antipsychotic drug action. Neuropsychopharmacology 21: S106-S115.

Millan MJ, Newman-Tancredi A, Audinot V, Cussac D, Lejeune F, Nicolas JP et al (2000). Agonist and antagonist actions of yohimbine as compared to fluparoxan at alpha(2)-adrenergic receptors (AR)s, serotonin (5-HT)(1A), 5-HT(1B), 5-HT(1D) and dopamine $D(2)$ and $D(3)$ receptors. Significance for the modulation of frontocortical monoaminergic transmission and depressive states. Synapse 35: 79-95.

Mongeau R, Blier P, de Montigny C (1997). The serotonergic and noradrenergic systems of the hippocampus: their interactions and the effects of antidepressant treatments. Brain Res Rev 23: 145-195.

Montgomery SA (1994). Long-term treatment of depression. $\mathrm{Br} J$ Psychiatry 26(Suppl): 31-36.

Newman-Tancredi A, Nicolas JP, Audinot V, Gavaudan S, Verriele $\mathrm{L}$, Touzard $\mathrm{M}$ et al (1998). Actions of alpha $_{2}$ adrenoceptor ligands at alpha $2 \mathrm{~A}$ and $5-\mathrm{HT}_{1 \mathrm{~A}}$ receptors: the antagonist, atipamezole, and the agonist, dexmedetomidine, are highly selective for alpha ${ }_{2 \mathrm{~A}}$ adrenoceptors. Naunyn Schmiedebergs Arch Pharmacol 358: 197-206.

Nicholas AP, Hökfelt T, Pieribone V (1996). The distribution and significance of CNS adrenoceptors examined with in situ hybridization. Trends Pharmacol Sci 17: 245-255.

Nicholas AP, Pieribone V, Hokfelt T (1993). Distributions of mRNAs for alpha-2 adrenergic receptor subtypes in rat brain: an in situ hybridization study. J Comp Neurol 328: $575-594$.

Ordway GA, Stockmeier CA, Cason GW, Klimek V (1997). Pharmacology and distribution of norepinephrine transporters in the human locus coeruleus and raphe nuclei. J Neurosci 17: 1710-1719.

Pan ZZ, Grudt TJ, Williams JT (1994). Alpha 1-adrenoceptors in rat dorsal raphe neurons: regulation of two potassium conductances. J Physiol 478: 437-447.

Paxinos G, Watson C (1986). The Rat Brain in Stereotaxic Coordinates. Academic Press: Sydney.

Peyron C, Luppi PH, Fort P, Rampon C, Jouvet M (1996). Lower brainstem catecholamine afferents to the rat dorsal raphe nucleus. J Comp Neurol 364: 402-413.

Peyron C, Petit JM, Rampon C, Jouvet M, Luppi PH (1998). Forebrain afferents to the rat dorsal raphe nucleus demonstrated by retrograde and anterograde tracing methods. Neuroscience 82: 443-468.

Pieribone VA, Nicholas AP, Dagerlind A, Hokfelt T (1994). Distribution of alpha-1 adrenoceptors in rat brain revealed by 
in situ hybridization experiments utilizing subtype-specific probes. J Neurosci 14: 4252-4268.

Romero L, Celada P, Artigas F (1994). Reduction of in vivo striatal 5 -hydroxytryptamine release by 8 -OH-DPAT after inactivation of Gi/G(o) proteins in dorsal raphe nucleus. Eur J Pharmacol 265: $103-106$.

Rosin DL, Talley EM, Lee A, Stornetta RL, Gaylinn BD, Guyenet PG et al (1996). Distribution of alpha 2C-adrenergic receptor-like immunoreactivity in the rat central nervous system. J Comp Neurol 372: 135-165.

Rouquier L, Claustre Y, Benavides J (1994). Alpha 1-adrenoceptor antagonists differentially control serotonin release in the hippocampus and striatum: a microdialysis study. Eur $J$ Pharmacol 261: 59-64.

Ruffolo RR, Waddell JE (1982). Receptor interactions of imidazolines. IX. Cirazolline is an alpha-1 adrenergic agonist and an alpha-2 adrenergic antagonist. J Pharmacol Exp Ther 222: 29-36.

Saavedra JM, Grobecker H, Zivin J (1976). Catecholamines in the raphe nuclei of the rat. Brain Res 114: 337-345.

Sakai K, Crochet S (2000). Serotonergic dorsal raphe neurons cease firing by disfacilitation during paradoxical sleep. Neuroreport 11: 3237-3241.

Sakai K, Salvert D, Touret M, Jouvet M (1977). Afferent connections of the nucleus raphe dorsalis in the cat as visualized by the horseradish peroxidase technique. Brain Res 137: 11-35.

Scheinin M, Lomasney JW, Hayden-Hixson DM, Schambra UB, Caron MG, Lefkowitz RJ et al (1994). Distribution of alpha 2adrenergic receptor subtype gene expression in rat brain. Brain Res Mol Brain Res 21: 133-149.

Sesack SR, Deutch AY, Roth RH, Bunney BS (1989). Topographical organization of the efferent projections of the medial prefrontal cortex in the rat: an anterograde tract-tracing study with Phaseolus vulgaris leucoagglutinin. J Comp Neurol 290: 213-242.

Sprouse JS, Aghajanian GK (1987). Electrophysiological responses of serotonergic dorsal raphe neurons to $5-\mathrm{HT}_{1 \mathrm{~A}}$ and $5-\mathrm{HT}_{1 \mathrm{~B}}$ agonists. Synapse 1: 3-9.

Steinbusch HWM (1981). Distribution of serotonin-immunoreactivity in the central nervous system of the rat. Cell bodies and terminals. Neuroscience 6: 557-618.

Stern WC, Johnson A, Bronzino JD, Morgane PJ (1981). Neurpharmacology of the afferent projections from the lateral habenula and substantia nigra to the anterior raphe in the rat. Neuropharmacology 20: 979-989.

Strazielle C, Lalonde R, Hebert C, Reader TA (1999). Regional brain distribution of noradrenaline uptake sites, and of alpha $_{1^{-}}$alpha $_{2^{-}}$and beta-adrenergic receptors in PCD mutant mice: a quantitative autoradiographic study. Neuroscience 94: 287-304.

Svensson TH, Bunney BS, Aghajanian GK (1975). Inhibition of both noradrenergic and serotonergic neurons in brain by the alpha-adrenergic agonist clonidine. Brain Res 92: 291-306.

Takagishi M, Chiba T (1991). Efferent projections of the infralimbic (area 25) region of the medial prefrontal cortex in the rat: an anterograde tracer PHA-L study. Brain Res 566: 26-39.

Talley EM, Rosin DL, Lee A, Guyenet PG, Lynch KR (1996). Distribution of alpha ${ }_{2 \mathrm{~A}}$-adrenergic receptor-like immunoreactivity in the rat central nervous system. J Comp Neurol 372: 111-134.

Tao R, Auerbach SB (1994). Anesthetics block morphine-induced increases in serotonin release in rat CNS. Synapse 18: 307-314.

Tao R, Hjorth S (1992). Alpha ${ }_{2}$-adrenoceptor modulation of rat ventral hippocampal 5-hydroxytryptamine release in vivo. Naunyn Schmiedebergs Arch Pharmacol 345: 137-143.

Tao R, Ma ZY, Auerbach SB (2000). Differential effect of local infusion of serotonin reuptake inhibitors in the raphe versus forebrain and the role of depolarization-induced release in increased extracellular serotonin. J Pharmacol Exp Ther 294: 571-579.

Tejani-Butt SM (1992). [ $\left.{ }^{3} \mathrm{H}\right]$ nisoxetine: a radioligand for quantitation of norepinephrine uptake sites by autoradiography or by homogenate binding. J Pharmacol Exp Ther 260: 427-436.

Tellez S, Colpaert F, Marien M (1999). Alpha ${ }_{2}$-adrenoceptor modulation of cortical acetylcholine release in vivo. Neuroscience 89: $1041-1050$.

Thase ME, Entsuah AR, Rudolph RL (2001). Remission rates during treatment with venlafaxine or selective serotonin reuptake inhibitors. Br J Psychiatry 178: 234-241.

Unnerstall JR, Kopajtic TA, Kuhar MJ (1984). Distribution of alpha-2 agonist binding sites in the rat and human central nervous system: analysis of some functional, anatomic correlates of the pharmacologic effects of clonidine and related adrenergic agents. Brain Res 319: 69-101.

Vandermaelen CP, Aghajanian GK (1983). Electrophysiological and pharmacological characterization of serotonergic dorsal raphe neurons recorded extracellularly and intracellularly in rat brain slices. Brain Res 289: 109-119.

Winzer-Serhan UH, Raymon HK, Broide RS, Chen Y, Leslie FM (1997a). Expression of alpha ${ }_{2}$ adrenoceptors during rat brain development-II. Alpha $2 \mathrm{C}$ messenger RNA expression and $\left[{ }^{3} \mathrm{H}\right]$ rauwolscine binding. Neuroscience 76: 261-272.

Winzer-Serhan UH, Raymon HK, Broide RS, Chen Y, Leslie FM (1997b). Expression of alpha ${ }_{2}$ adrenoceptors during rat brain development-I. Alpha $\mathrm{A}_{\mathrm{A}}$ messenger RNA expression. Neuroscience 76: 241-260. 